\title{
A combined periodic DFT and QM/MM approach to understand the radical mechanism of the catalytic production of methanol from glycerol.
}

\author{
Mala A. Sainna, Sachin Nanavati, Constance Black, Louise Smith, Karl Mugford, Harry \\ Jenkins, Mark Douthwaite, Nicholas F. Dummer, C. Richard A. Catlow, Graham J. \\ Hutchings, Stuart H. Taylor, Andrew J. Logsdail ${ }^{*}$ and David J. Willock. ${ }^{*}$ \\ Cardiff Catalysis Institute, School of Chemistry, Cardiff University, Cardiff, CF10 3AT \\ *corresponding authors: logsdaila@cardiff.ac.uk,willockdj@cardiff.ac.uk
}

\begin{abstract}
The production of methanol from glycerol over a basic oxide, such as $\mathrm{MgO}$, using high reaction temperatures $\left(320{ }^{\circ} \mathrm{C}\right)$ is a promising new approach to improving atom efficiency in the production of biofuels. The mechanism of this reaction involves the homolytic cleavage of the $\mathrm{C}_{3}$ feedstock, or its dehydration product hydroxyacetone, to produce a hydroxymethyl radical species which can then abstract an $\mathrm{H}$ atom from other species. Obtaining a detailed reaction mechanism for this type of chemistry is difficult due to the large number of products present when the system is operated at high conversions. In this contribution we show how DFT based modelling studies can provide new insights into likely reaction pathways, in particular the source of $\mathrm{H}$ atoms for the final step of converting hydroxymethyl radicals to methanol. We show that water is unlikely to be important in this stage of the process, $\mathrm{C}-\mathrm{H}$ bonds of $\mathrm{C}_{2}$ and $\mathrm{C}_{3}$ species can give an energetically favourable pathway and that the disproportionation of hydroxymethyl radicals to methanol and formaldehyde produces a very favourable route. Experimental analysis of reaction products confirms the presence of formaldehyde.
\end{abstract}

The calculations presented in this work also provides new insight into the role of the catalyst surface in the reaction showing that the base sites of the $\mathrm{MgO}(100)$ are able to deprotonate hydroxymethyl radicals but not methanol itself. In carrying out the calculations we also show how periodic DFT and QM/MM approaches can be used together to obtain a rounded picture of molecular adsorption to surfaces and homolytic bond cleavage which are both central to the reactions studied.

\section{Introduction}

The production of biofuels from plant oils is an established route to the production of transportation fuels from renewable sources. Biodiesel is manufactured via the transesterification of natural triglyceride oils with methanol, giving approximately $90 \mathrm{wt} \%$ yield of fatty acid methyl esters (biodiesel) and a $10 \mathrm{wt} . \%$ crude glycerol by-product. ${ }^{1}$ Glycerol is also obtained from other sustainable biofuel resources such as recycled cooking oils. ${ }^{2}$ To reduce the waste in these processes a range of uses of glycerol have been proposed ${ }^{3}$ and developed, ${ }^{4}$ mainly focusing on $\mathrm{C}_{3}$ platform molecules to produce products that are traditionally derived from propylene in the peterochemical industry. ${ }^{5}$ For example, acrolein (propenal) $\mathrm{CH}_{2} \mathrm{CHCHO}$ can be obtained from the Bronsted acid catalysed dehydration of glycerol. ${ }^{6}$ Selective hydrogenolysis, oxidation and steam reforming to produce bio-hydrogen 
have also been pursued as promising research areas for the valorisation of glycerol and a number of reviews have appeared..$^{3,7,8}$

We have recently shown how aqueous glycerol can be reacted in the vapour phase over basic or redox active oxide catalysts in a flow reactor to produce methanol with high selectivity at $25 \%$ conversion. ${ }^{9}$ This finding is significant, as it could point the way to producing the methanol required for the transesterification reaction directly from the glycerol side product and so increase the atom efficiency of biofuel production. In subsequent work we have concentrated on identifying full product distributions for $\mathrm{CeO}_{2}{ }^{10}$ and for $\mathrm{MgO}$ as the most promising redox and basic catalysts respectively. At temperatures between $360{ }^{\circ} \mathrm{C}$ and $440{ }^{\circ} \mathrm{C}$, using $\mathrm{MgO}$ catalysts, we have scoped out a plausible pathways which can account for the range of observed products ${ }^{11}$ and a simplified version is given in Scheme 1. This version focuses on the routes from glycerol to methanol and does not include products that have been assigned to secondary reactions. Glycerol, 1, can undergo dehydration reactions to form hydroxyacetone, $\mathbf{3}$, and acrolein, $\mathbf{2}$ which are both observed as major products. At the high temperatures used in these reactions glycerol and hydroxyacetone can also undergo homolytic $\mathrm{C}-\mathrm{C}$ bond cleavage to produce a $\mathrm{C} 1$ hydroxymethyl radical precursor to methanol, 4 , and a $\mathrm{C}_{2}$ radical side product (6 in the case of glycerol and $\mathbf{5}$ in the case of hydroxyacetone). These radical species can then abstract an $\mathrm{H}$ atom from some other reactant to generate methanol, 7, and give the additional products ethylene glycol, 8, ethanol, 9 and acetaldehyde, 10. This paper will use DFT based modelling to discuss the energetics of the final step for methanol production by considering the interaction of the hydroxymethyl radical $\bullet \mathrm{CH}_{2} \mathrm{OH}$, 4, with other molecules in the system using both periodic DFT slab models and a QM/MM approach to consider the $\mathrm{H}$ transfer reactions on the most stable (100) surface of the $\mathrm{MgO}$ catalyst and so identify the most energetically favourable $\mathrm{H}$ donor in this final step of the reaction. We compare the calculated data with low conversion reaction results from catalysts calcined at difference temperatures. Low conversion is used to limit the contribution of secondary reactions and high temperature annealing produces $\mathrm{MgO}$ with low defect densities allowing us to discern the contribution of the (100) surface.

$\mathrm{MgO}$ has been widely studied using computational techniques; its rock salt structure leads to high stability for the (100) facet and correspondingly low basicity as measured by calculated water adsorption energies. ${ }^{12}$ Direct comparison to experimental spectroscopic work also shows that carbonate species are more readily formed on base sites associated with steps and defects than on the flat (100) surface. ${ }^{13}$ Calculations commonly model the system using either quantum 

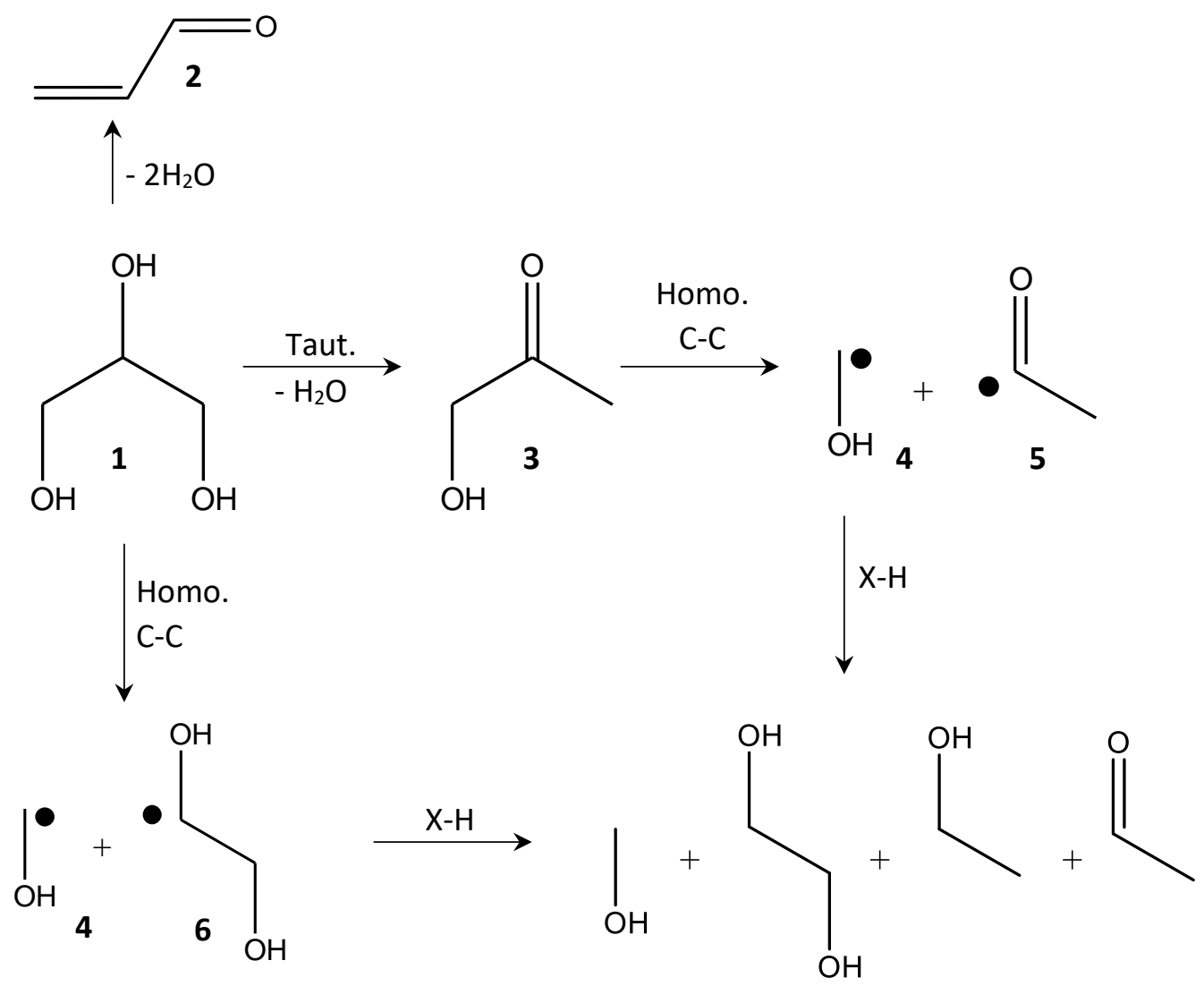

7

8

9

10

Scheme 1: Simplified reaction scheme for the production of methanol from glycerol.

or molecular mechanics (QM and MM, respectively), with both approaches offering strengths and weaknesses: QM offers high accuracy energetics with no system specific parameterisation, though at a much greater cost than parameterised MM approaches. As the electronic structure is explicitly calculated in QM approaches it is also more readily able to describe the bond breaking and forming processes that are key in catalysis. In surface catalysed reactions there is a general concept of an active site located on the surface consisting of a few atoms that take part in the catalytic reaction with most of the structure providing only long range electrostatic and van der Waals interactions with adsorbates. The development of hybrid quantum/molecular mechanical approaches has been beneficial for catalysis particularly when employing wide bandgap materials such as $\mathrm{MgO}$; the high stability and low polarizability of these materials mean that it is relatively facile to introduce a small, focused QM region surrounded by an polarisable MM region with minimal geometric and electronic inconsistences around the interfacial region. ${ }^{14}$ The reduced number of electrons that need be considered in the focused QM region allows for higher levels of theory than those which are accessible with periodic 
QM, with accurate long range response ensured through the dielectric response of the surrounding MM region.

The QM/MM approach has previously been applied to $\mathrm{MgO}$ for modelling its role either as a catalyst or catalyst support. As a support material, hybrid embedding models have been used to consider deposition of single transition metal atoms ${ }^{15}$ as well as small nanoclusters of $\mathrm{Cu}$, $\mathrm{Ag}$ and $\mathrm{Au},{ }^{16}$ though commonly the embedding environment is taken as fixed point charges unable to provide a dielectric response. The interaction of the $\mathrm{MgO}$ surface directly with reactants and products has also been an area of study with hybrid QM/MM, as the approach allows use of high-level theory to calculate bond energies. Boese and Sauer studied the adsorption of $\mathrm{CO}, \mathrm{CH}_{4}$ and $\mathrm{C}_{2} \mathrm{H}_{6}$ on $\mathrm{MgO}$ with hybrid QM/QM approaches to obtain coupled cluster $(\mathrm{CCSD}(\mathrm{T}))$ and MP2 level accuracy. ${ }^{17}$ Sicolo and Sauer ${ }^{18}$ considered further the interaction of $\mathrm{CO}$ with neutral and charged F-centres on $\mathrm{MgO}$ (100) and Downing et al. ${ }^{19}$ studied the reactivity of $\mathrm{CO}_{2}$ over the same surface defects, both using a QM/MM embeddedcluster model; it was observed that the molecules bonded strongly to the $\mathrm{F}^{-}$and $\mathrm{F}^{+}$-centres, but did not bind to the ionised $\mathrm{F}^{2+}$-centre. They also showed that $\mathrm{CO}_{2}$ reacts with terrace oxygen ions to form a carbonate species.

In this work, we consider the final step in the production of methanol from glycerol; i.e. the transfer of a hydrogen atom to a hydroxymethyl radical and consider likely $\mathrm{H}$ atom donors that could be used to generate the methanol product in this way. We also examine an important methodological issue by comparing the efficiency and accuracy of periodic DFT and QM/MM approaches in the calculation of the key reaction intermediates for this step of the process. The calculations are based on models of the $\mathrm{MgO}$ (100) plane, which is the most stable and wellstudied facet of $\mathrm{MgO}$, but is also known experimentally to have low basicity. To test the validity of the computational work, new experimental data have also been obtained with low surface area $\mathrm{MgO}$ and at low catalytic conversion levels, so that the experimental and simulation work are relevant to the same material. These results are examined to test the validity of the mechanistic conclusions from the calculated results.

\section{Methods}

\section{Periodic DFT calculations}

Periodic planewave calculations were carried out using the VASP code ${ }^{20}$ with core states represented using the projector augmented-wave (PAW) method. ${ }^{21}$ We select the PBEsol functional $^{22}$ for consistency with the QM/MM calculations described below. We have also 
considered dispersion interaction corrections using the Grimme D3 approach ${ }^{23}$ (PBEsol+D3). All optimised structures were assessed on the residual forces with a acceptance criterion of $0.01 \mathrm{eV} \AA^{-1}$. In order to obtain forces within this value, we used a planewave cut off of $800 \mathrm{eV}$ and an SCF convergence criteria of at least $1 \times 10^{-6} \mathrm{eV}$.

$\mathrm{MgO}$ has the rock salt structure with space group $F m \overline{3} m$, as a basis for all periodic calculations the face centred cubic (fcc) unit cell was optimised using the PBEsol functional ${ }^{22}$ within the VASP code at a series of cell volumes and the resulting energy $v s$ cell volume curve fitted to the Murnaghan equation of state ( Supplementary Information section S1). For these bulk calculations we used a $k$-point sampling of $5 \times 5 \times 5$. The resulting cell vector of $4.207 \AA$ agrees well with the low temperature $(77 \mathrm{~K})$ experimental cell parameter ${ }^{24}$ of $4.203 \AA$ A. Similarly, the calculated bulk modulus of $156 \mathrm{GPa}$ agrees well with experiment ${ }^{25}(154 \mathrm{GPa})$ and earlier calculations $^{26}$ (141 GPa (PBE)).

The $\mathrm{MgO}(100)$ is the most stable facet of the solid as it is formed from charge neutral sheets exposing only 5 co-ordinate $\mathrm{Mg}^{2+}$ cations and $\mathrm{O}^{2-}$ anions, $\mathrm{Mg}_{5 \mathrm{c}}$ and $\mathrm{O}_{5 \mathrm{c}}$ sites respectively. For periodic calculations involving the (100) surface, a slab consisting of 5 atomic layers was constructed based on the optimised bulk. The slab area was a $2 \times 2$ expansion of the face of the fcc cube with a $15 \AA$ gap between periodic slab images in the direction perpendicular to the surface. For slab calculations, the $k$-point sampling density was reduced to of $3 \times 3 \times 1$. During optimisation, the lowest layer of ions was frozen at their relaxed bulk positions. The calculated surface energies for the $2 \times 2$ slab structure used in the periodic DFT work presented here are $1.07 \mathrm{~J} \mathrm{~m}^{-2}$ (PBEsol) and $1.50 \mathrm{~J} \mathrm{~m}^{-2}$ (PBEsol+D3), which compare well to earlier calculations using both force field ( e.g. Parker et al. ${ }^{27}$ obtained $1.25 \mathrm{~J} \mathrm{~m}^{-2}$ ) and gradient corrected DFT, (e.g. Finocchi and Goniakowski ${ }^{28}$ reported $0.90 \mathrm{~J} \mathrm{~m}^{-2}$ using the PBE functional with the VASP code ).

\section{QM/MM calculations}

As discussed above, an alternative method for the consideration of reactions at the surface of solids at an affordable computational cost is the use of quantum mechanics/molecular mechanics (QM/MM) methods. In these methods the system is divided into different regions with different computational descriptions. The calculation of the QM/MM energy, $E_{t o t}(Q M, M M)$, for a given system can be expressed as:

$$
E_{\text {tot }}(Q M, M M)=E_{Q M}(Q M)+E_{M M}(M M)+E_{\text {int }}(Q M, M M) \text {, }
$$


where the labels in subscripts on the right-hand side refer to the computational approach used for each energy term. Density functional theory (DFT) is used for QM, and classical interatomic potentials for $\mathrm{MM} ; E_{\text {int }}$ refers to the interaction energy between QM and MM regions of the calculation. An expanded pictorial view of the QM/MM model used in these calculations is shown in Figure 1. The labels in parentheses in equation 1 refer to the regions where each calculation is carried out - either the QM, or the $\mathrm{MM}$ region. The $\mathrm{QM}$ region consists of a 2 layer $\mathrm{MgO}(100)$ cluster containing 50 ions, this choice of region shape ensures that the QM region is formally charge neutral and has no net dipole.

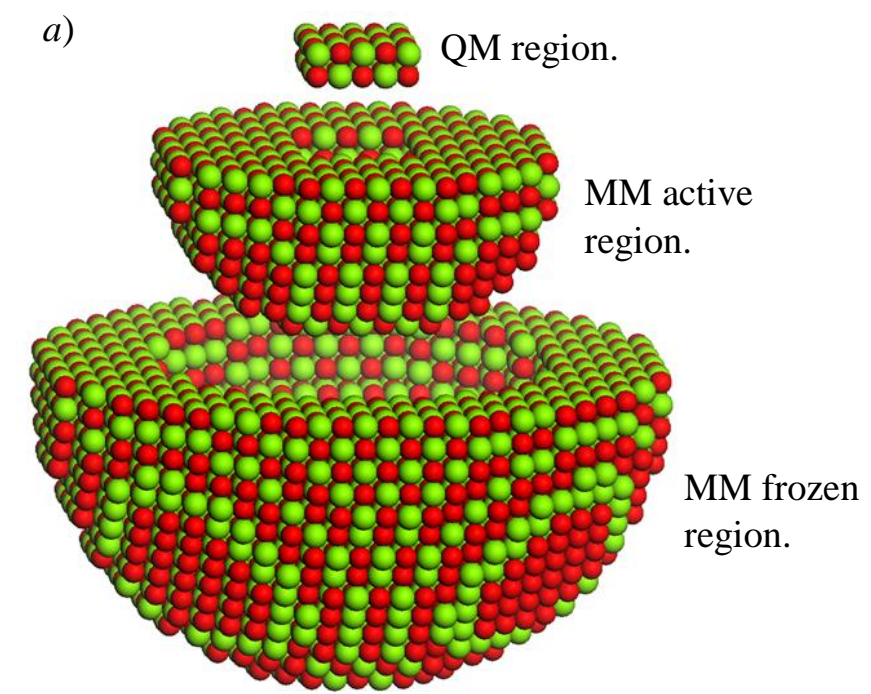

b)

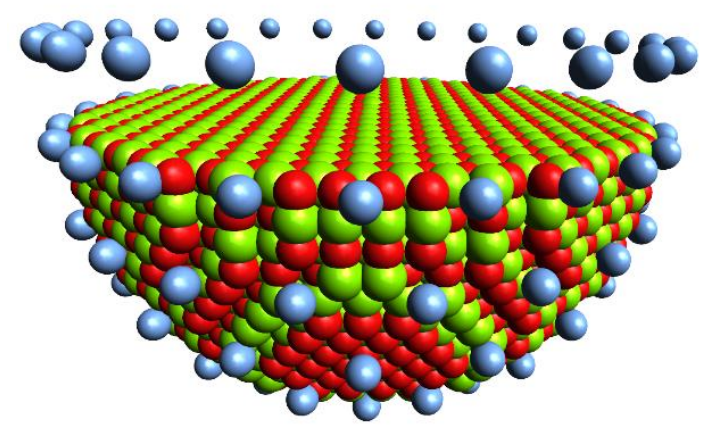

Figure 1.a) An expanded view of the QM/MM simulation regions used in these calculations. b) The complete $\mathrm{QM} / \mathrm{MM} \mathrm{MgO}(100)$ simulation system including electrostatic correction charges outside of the MM region. Atom colours; yellow: $\mathrm{Mg}$, red: $\mathrm{O}$, blue: correction charge site.

The MM calculations employ an empirically parametrised, classical representation of the interactions between ions. In this case we have used a formal charge $\left(\mathrm{Mg}^{2+}, \mathrm{O}^{2-}\right)$ model of magnesium oxide with a shell model potential to describe the polarizability of the $\mathrm{O}^{2-}$ anions in the $\mathrm{MM}$ regions. Non-coulombic repulsion/dispersion interactions are represented with Buckingham potentials, ${ }^{29}$ full details of the parameters employed are given in Supplementary Information (S2). In addition, for the QM calculation, a pseudopotential is positioned on each $\mathrm{Mg}^{2+}$ ion in the active $\mathrm{MM}$ region. This pseudopotential has been fitted to replicate the core electrons of a gaseous $\mathrm{Mg}^{2+}$ ion using the package fhi98pp. ${ }^{30}$ Its role is to prevent electron density in the QM region from moving to surround the positive MM point charges at $\mathrm{Mg}$ sites in the MM region. 
This work uses a solid-state QM/MM embedded cluster model of the $\mathrm{MgO}$ (100) surface to study surface catalysis. The hemispherical cluster shown in Figure $1 a$ is cut out of an extended surface as described below, with the QM region - and the surface adsorbates of interest - at the centre of the flat face of the hemisphere. The QM region is an active region, which means the atoms are relaxed during calculations. Surrounding the QM region is the active-MM region, in which atoms and shells are relaxed during calculations following the interatomic potentials defined in the force field. Beyond the active-MM region is the fixed-MM region, in which the atoms are not relaxed at all during calculations; this enforces the long-range bulk structure of the oxide. Finally, this hemisphere of atoms is embedded within an arrangement of point charges, fitted to reproduce the fully periodic electrostatic potential in the QM region.

The energy and forces for the small number of atoms in the QM region ( $~ 50-70$ when adsorbates are included) are obtained using quantum mechanical methods as implemented in the Fritz-Haber Institute ab initio molecular simulation package, FHIaims. ${ }^{31}$ The remaining atoms in the MM regions of the hemispherical cluster are treated using the computational program package GULP. ${ }^{32-34}$ The Chemshell ${ }^{35}$ modular software package for QM/MM simulation is used to link QM and MM calculations and makes use of the geometry optimisation library DL-FIND ${ }^{36}$ code. Chemshell manages the interaction between the two regions, allowing the QM calculation to benefit from the presence of the electrostatic environment of the MM region which can undergo longrange polarisation via the shell model in response to change in the charge density around the site of interest. The embedding charges (Figure $1 b$ ) are used to ensure that the electrostatic field of a fully periodic GULP calculation is reproduced in the QM region during QM/MM calculations.

In order to reduce the computational cost, the quantum mechanical optimisation was carried out using the GGA functional PBEsol ${ }^{22}$ in conjunction with FHI-aims "tight" basis sets for all atoms in the QM region. The "tight" basis set is a set of numerical hydrogen like orbital functions that give equivalent accuracy to that of a TZVP basis set in Gaussian function-based codes, intended to approach basis set convergence to within a few meV. The tight basis set contains at least two valence shell radial functions on each atom and polarisation functions of angular momenta up to $f$ orbitals for $\mathrm{Mg}$, up to $g$ orbitals for elements in the first two rows except for $\mathrm{H}$ which has angular momenta up to $d$ orbitals available. Energies using hybrid PBE0 ${ }^{37}$ functionals were obtained following self-consistent-field electronic structure calculations at the optimised PBEsol 
structures, with the long-range polarisation of shells in the MM calculation also optimised to self-consistency. Calculations using both $\mathrm{MgO}$ and $\mathrm{TiO}_{2}$ as examples have shown that there is good agreement between the optimised structures for periodic calculations between the PBEsol functional and hybrid functional approaches using FHI-aims. ${ }^{38}$ The choice of PBESol also allows comparison of periodic and QM/MM results using the same functional. Although dispersion corrections are available in FHIaims we have not used them in this work as the dispersion interaction between the MM and the QM region has not been parameterised. To assess the effect of long-range dispersion interactions we will discuss the periodic PBEsol+D3 calculation results alongside the PBE0 data.

Adsorbates modelled in the QM region were treated with the same QM theory as the rest of the QM region. However, no extra potential terms are added to account for the interactions between the adsorbates with the MM region. These interactions would need to be independently parameterised, but since, in most cases, the shortest distance between an adsorbate atom and an MM atom is more than $6 \AA$, they were considered negligible.

Construction of a surface QM/MM cluster follows a systematic procedure as outlined in previous work. ${ }^{38} \mathrm{~A}$ series of periodic calculations are run using the same QM or MM methodology to be used in the final cluster to assess the consistency of the two treatments. Firstly, the bulk structure is calculated using periodic DFT within FHI-aims using the PBEsol functional and tight basis set with a $k$-grid setting of $6 \times 9 \times 9$, which is then rearranged into a periodic DFT slab calculation, with one side fixed, to calculate surface relaxation. The depth of this slab is increased until the surface formation energy converges. Next, the fixed side of the slab was extended to make slab about $100 \AA$ deep. This extended slab is used in a periodic FF calculation to relax the shells, representing oxygen ion polarizability, only. Relaxing the shells at the surface is necessary to ensure that the MM region, and the fixed MM region in particular, has the correct surface polarisation.

The hemisphere used as the QM/MM model was cut out of the resulting slab representation of the surface and embedded within an arrangement of point charges (see Figure $1 b$ ) fitted to reproduce the electrostatic potential of the fully periodic FF slab calculations in the QM region. The hemisphere used in this work has a radius of $55 \AA$, with an active region of radius $25 \AA$. The QM region is a $5 \times 5$ square of atoms on the surface, 2 layers deep. This QM region choice was found to give more accurate 
adsorption and defect formation energies than alternate shapes containing the same number of atoms. ${ }^{38}$ A $5 \times 5$ surface area was chosen as this is sufficiently large to accommodate the adsorbates considered in this work without molecular species interacting with atoms at the edge of the oxide surface QM cluster.

\section{Catalyst preparation}

An $\mathrm{MgO}$ catalyst was prepared using the reflux technique reported previously. ${ }^{9}$ The asreceived metal hydroxide was calcined to $450{ }^{\circ} \mathrm{C}$ for $2 \mathrm{~h}\left(10{ }^{\circ} \mathrm{C} \mathrm{min}{ }^{-1}\right.$, static air). The resulting metal oxide was refluxed in deionised water $\left(15 \mathrm{ml} \mathrm{g}^{-1}\right)$ for $3 \mathrm{~h}$ to form a slurry and then dried at $110{ }^{\circ} \mathrm{C}$ for 24 hours. The material was then calcined under nitrogen at $450{ }^{\circ} \mathrm{C}, 650^{\circ} \mathrm{C}$ or 750 ${ }^{\circ} \mathrm{C}$ with the temperature achieved using a ramp rate of $10{ }^{\circ} \mathrm{C} \mathrm{min}^{-1}$. Once the sample was at the desired temperature it was held for $3 \mathrm{~h}$ in flowing nitrogen to obtain the final oxide catalyst materials designated $\mathrm{MgO}$ (450), $\mathrm{MgO} \_(650)$ and $\mathrm{MgO}$ (750) depending on the temperature of the calcination step.

\section{Catalyst testing}

Reactions were performed using a gas-phase plug flow micro-reactor. Typically, aqueous glycerol solutions (50 wt.\%) were introduced into a preheater and vaporiser $\left(305{ }^{\circ} \mathrm{C}\right)$ using a HPLC pump at a flow rate of $0.016 \mathrm{~mL} \mathrm{~min}^{-1}$. The glycerol feed was swept through the reactor using argon as carrier gas $\left(50 \mathrm{~mL} \mathrm{~min}^{-1}\right)$. All lines were heated to $300{ }^{\circ} \mathrm{C}$ (pre-catalyst bed) and $100{ }^{\circ} \mathrm{C}$ (post-catalyst bed) to prevent any internal condensation. Catalysts were pelleted, crushed and sieved to a uniform particle size $(250-425 \mu \mathrm{m})$ prior to testing. Typically, $0.1 \mathrm{~g}$ of catalyst was combined with silicon carbide to a uniform volume $(0.5 \mathrm{~mL})$ and packed into an $8 \mathrm{~mm}$ inner diameter stainless steel tube between two plugs of quartz wool. The resultant mass velocity and space velocity studied was $30000 \quad \mathrm{~L}_{\mathrm{Ar} \mathrm{h}} \mathrm{kg}^{-1} \mathrm{~kg}^{-1}$ and 20000 $\mathrm{L}_{\mathrm{Ar}} \mathrm{h}^{-1} \mathrm{~L}_{\mathrm{cat}}{ }^{-1}$, respectively. Reactions were carried out at $320 \pm 1{ }^{\circ} \mathrm{C}$ in an oven controlled by a PID temperature controller with a thermocouple placed in the catalyst bed. Liquid reaction products were collected using an ice cold stainless steel trap. A gas bag was attached at the exit line to collect the gaseous products.

\section{Product analysis}

Liquid reaction products and carbon based gas reaction products were analysed offline using an Agilent 7890B gas chromatograph equipped with a capillary column (ZB-Wax plus, $30 \mathrm{~m}$ $\times 0.53 \mathrm{~mm} \times 1 \mu \mathrm{m})$. Cyclohexanol was used as an external standard for quantification of the 
liquid phase products. $\mathrm{H}_{2}$ and $\mathrm{O}_{2}$ were analysed using a Varian CP3380 gas chromatograph equipped with a Porapak Q column.

Qualitative formaldehyde analysis was also performed offline using an Agilent 1200 Infinity HPLC equipped with a C18 column (Agilent InfinityLab Poroshell 120 SB-C18, 150 x 4.6 mm $\mathrm{x} 2.7 \mu \mathrm{m}$ ). Formaldehyde was derivatized with 2,4-dinitrophenylhydrazine (DNPH) to form a formaldehyde-DNPH adduct, which can be analysed by UV at a wavelength of $360 \mathrm{~nm}$. Derivatization was achieved by attaching an LpDNPH cartridge (Volume $6 \mathrm{~mL}$, bed weight of $1 \mathrm{~g}$ ) to the end of the reactor before the cold trap, derivatized compounds were subsequently eluted from the cartridge with acetonitrile for analysis.

\section{Results and Discussion}

As discussed above, at the high temperatures used experimentally we propose that the observed product distribution can be understood in terms of radical processes such as homolytic cleavage of the C-C bonds in glycerol or the main dehydration product hydroxyacetone. ${ }^{11}$ For either route to produce methanol, the hydroxymethyl radical must receive a hydrogen atom from some source in the final step to produce methanol, Scheme 2:

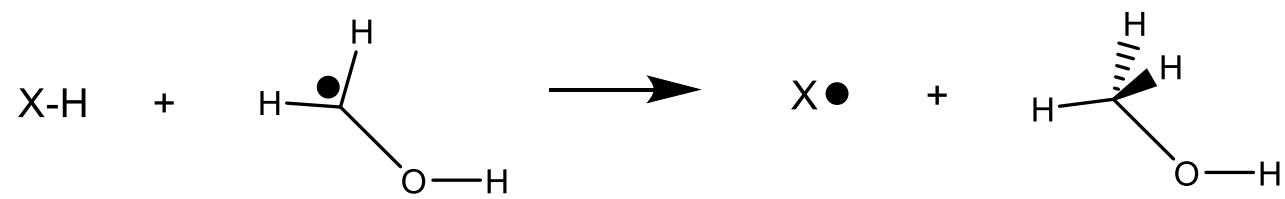

Scheme 2. Hydrogen transfer to produce methanol from hydroxymethyl radical.

Under reaction conditions, there will be water, glycerol and other hydrogen containing intermediates present that could act as a hydrogen source. In this study, we have used DFT calculations to consider which of these alternatives would give a low energy route for the required hydrogen transfer. We have also taken the opportunity to compare the performance of standard periodic GGA calculations (PBEsol) using plane wave basis sets with an embedded QM/MM approach via the ChemShell software. The QM/MM approach allows the extension of the available QM approaches to hybrid functionals and post Hartree Fock methods available for molecular calculations at a fraction of the computational cost for the equivalent periodic calculations.

Firstly, we have looked at the reagents present that could donate an $\mathrm{H}$ atom and calculated the bond dissociation energies for the X-H cleavage step of the reaction for each species in isolation without inclusion of the catalyst surface (Table 1). Where a molecule contains more than one 
$\mathrm{X}-\mathrm{H}$ bond, each possibility for radical formation has been considered; atom labelling is defined in Figure 2. The BDE of water and the smaller molecular species of interest have been measured experimentally ${ }^{39}$ and are also included in the table, where available. Table 1 also reports the calculated unsigned mean error from a comparison of the different DFT methods and the available experimental values. We note that the calculated errors for hybrid PBE0 method are notably smaller than when gradient corrected DFT alone is used. Water stands out in this comparison with PBEsol overestimating the BDE compared to experiment by $66 \mathrm{~kJ} \mathrm{~mol}^{-}$ ${ }^{1}$ while PBE0 gives a value within $11 \mathrm{~kJ} \mathrm{~mol}^{-1}$ of the reference. Table 1 also shows that, in general, using the PBE0 method at the PBEsol optimised structures (PBE0/PBEsol) gives the same BDE values as full optimisation within a few $\mathrm{kJ} \mathrm{mol}^{-1}$. This is the approach used later in the QM/MM calculations of reaction energies over the $\mathrm{MgO}$ (100) surface, and the close agreement here means that the additional computational overhead of optimisation of large QM/MM models at the PBE0 level can be avoided.

For glycerol, PBEsol calculations suggest that the formation of a carbon centred radical at $\mathrm{C}_{2}$ is some $13 \mathrm{~kJ} \mathrm{~mol}^{-1}$ lower in energy than that for a $\mathrm{C}_{1}$ radical, as would be expected as the secondary carbon should give a more stable radical than the primary carbon. However, in the hybrid approach of PBE0, this decreases to a difference of $5 \mathrm{~kJ} \mathrm{~mol}^{-1}$. At the PBE0 level, all the $\mathrm{C}_{2}$ or $\mathrm{C}_{3}$ molecules have $\mathrm{BDE}$ values around $100 \mathrm{~kJ} \mathrm{~mol}^{-1}$ lower than water, meaning that the supply of $\mathrm{H}$ from these sources should be significantly easier than from water. Using the BDE values from Table 1 to estimate the energy change for the reaction shown in Scheme 2 suggests a value of $94 \mathrm{~kJ} \mathrm{~mol}^{-1}$ taking $\mathrm{H}$ from water, and values of $-10 \mathrm{~kJ} \mathrm{~mol}^{-1},-75 \mathrm{~kJ} \mathrm{~mol}^{-1}$ and $-4 \mathrm{~kJ} \mathrm{~mol}^{-1}$ for the most favourable $\mathrm{H}$ transfers from glycerol, hydroxyacetone and ethylene glycol, respectively. The values suggest that the process should lead to carbon centred radicals for each of the alcohols. In addition, a very low BDE for the hydroxymethyl alcohol group suggests that we should also consider a disproportionation reaction in which two $\bullet \mathrm{CH}_{2} \mathrm{OH}$ moieties combine to form formaldehyde and methanol. The PBE0 BDE values in Table 1 gives a reaction energy of $-254 \mathrm{~kJ} \mathrm{~mol}^{-1}$ for this radical termination process.

In the next section we compare the adsorption of water, ethylene glycol, $\bullet \mathrm{CH}_{2} \mathrm{OH}$ and methanol on the $\mathrm{MgO}(100)$ surface to check the consistency of periodic and QM/MM approaches using the same functional and then to consider the effects of dispersion corrections with periodic methods and hydrid functionals with QM/MM. Ethylene glycol is chosen as the representative alcohol C-H donor as the periodic boundary conditions and QM/MM QM region size places a size restriction on the adsorbates that can be considered. 
Table 1: Calculated bond dissociation energies for various reactant species.

\begin{tabular}{|c|c|c|c|c|}
\hline Molecule/bond & $\begin{array}{c}\text { BDE } \\
\text { PBEsol }\end{array}$ & $\begin{array}{l}\text { BDE } \\
\text { PBE0 }\end{array}$ & $\begin{array}{c}\text { BDE } \\
\text { PBE0/PBEsol }\end{array}$ & $\begin{array}{c}\mathrm{DH}_{298^{c}} \\
\text { expt. }\end{array}$ \\
\hline & $/ \mathrm{kJ} \mathrm{mol}^{-1}$ & $/ \mathrm{kJ} \mathrm{mol}^{-1}$ & $/ \mathrm{kJ} \mathrm{mol}^{-1}$ & $/ \mathrm{kJ} \mathrm{mol}^{-1}$ \\
\hline glycerol $\mathrm{C}_{1} \mathrm{O}-\mathrm{H}$ & 456 & 447 & 455 & \\
\hline glycerol $\mathrm{C}_{2} \mathrm{O}-\mathrm{H}$ & 443 & 460 & 462 & \\
\hline glycerol $\mathrm{C}_{1}-\mathrm{H}$ & 418 & 409 & 410 & \\
\hline glycerol $\mathrm{C}_{2}-\mathrm{H}$ & 405 & 404 & 401 & \\
\hline hyd-act ${ }^{a} \mathrm{C}_{1} \mathrm{O}-\mathrm{H}$ & 477 & 474 & 477 & \\
\hline hyd-act ${ }^{a} \mathrm{C}_{1}-\mathrm{H}$ & 339 & 339 & 341 & \\
\hline hyd-act ${ }^{a} \mathrm{C}_{3}-\mathrm{H}$ & 426 & 415 & 416 & \\
\hline e-glycol ${ }^{b} \mathrm{O}-\mathrm{H}$ & 462 & 444 & 445 & \\
\hline e-glycol ${ }^{b} \mathrm{C}-\mathrm{H}$ & 413 & 409 & 408 & \\
\hline methanol C-H & 426 & 414 & 414 & 402 \\
\hline methanol O-H & 467 & 447 & 447 & 438 \\
\hline$\bullet \mathrm{CH}_{2} \mathrm{O}-\mathrm{H}$ & 163 & 161 & 161 & 126 \\
\hline water $\mathrm{HO}-\mathrm{H}$ & 563 & 508 & 508 & 497 \\
\hline unsigned error ${ }^{d}$ & 39 & 17 & 17 & \\
\hline
\end{tabular}

Notes: $a$ ) hydroxyacetone, $b$ ) ethylene glycol. Calculations carried out with FHI-aims using a tight basis throughout. $c$ ) Experimentally estimated homolytic bond dissociation enthalpies at $298 \mathrm{~K}$, taken from reference ${ }^{39}, d$ ) unsigned average energy difference between calculated BDE and experimental $\mathrm{DH}_{298}$ values (where available).

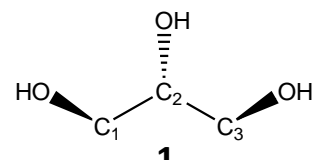

1

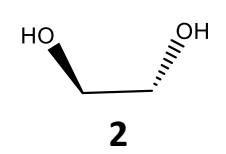

2<smiles>CC(=O)CO</smiles>

3

Figure 2: Organic molecules used as molecules present that could donate $\mathrm{H}$.

\section{Adsorption to the $\mathrm{MgO}(100)$ surface.}

The next step in the calculations was to use the adsorption of some example species in the reaction to the $\mathrm{MgO}(100)$ as a way to compare the performance of the periodic and QM/MM calculations, which also allows us to look at the importance of the choice of functional and the inclusion of dispersion interactions. Water on $\mathrm{MgO}(100)$ has been studied extensively with DFT methods. ${ }^{12,40}$ A single water molecule adsorbs without dissociation on the surface with favourable interactions of the oxygen atom lone pair electron density with an $\mathrm{Mg}_{5 \mathrm{c}}$ cation and 
the $\mathrm{H}$ atoms interacting with surface basic $\mathrm{O}_{5 c}$ anions. In this configuration periodic DFT calculations using a PBEsol functional and the parameters detailed in the methodology section gives an estimated adsorption energy of $-60 \mathrm{~kJ} \mathrm{~mol}^{-1}$ (as summarised in Table 2). Using the same functional in ChemShell with the parameters and cluster sizes detailed earlier we obtain $-65 \mathrm{~kJ} \mathrm{~mol}^{-1}$. For this system we have also considered the effect of the interaction of periodic images of the adsorbate in the periodic calculation which will not be present in the QM/MM approach. Section S3 details the comparison of water adsorption using three progressively larger slab calculations. The smallest of these has the area of a single fcc cubic unit cell and gives an estimate for the adsorption energy of $-57.8 \mathrm{~kJ} \mathrm{~mol}^{-1}$, the value falls to $-60.4 \mathrm{~kJ} \mathrm{~mol}^{-1}$ for the largest slab $(3 \times 3)$ which has a surface area of $159 \AA^{2}$, which suggests that, for the smallest surface area slab, there is significant adsorbate-adsorbate repulsion. Fitting a simple inverse power law to account for this effect gives an infinite dilution estimate for the water adsorption energy of $-61.6 \mathrm{~kJ} \mathrm{~mol}^{-1}$. We note that in these calculations we have used a $k$-point sampling mesh of $3 \times 3 \times 1$ for all cell sizes so there will also be some influence of the accuracy of the band structure with the largest unit cells giving a more highly converged result. A second difference between the two approaches is the importance of basis set superposition error (BSSE). In the QM/MM approach a localised basis set is used in the representation of the electronic structure of the inner region and so the calculation of the adsorption energies will be subject to BSSE, which is not the case for the periodic calculation as the basis set of planewaves depends only on the periodicity of the cell and the planewave cut off, which are the same for the calculation of the combined adsorbate/surface and their isolated reference states. We have estimated the BSSE correction for the QM/MM case of water on $\mathrm{MgO}(100)$ using the counterpoise approach ${ }^{41}$ and obtain an estimate of $2.5 \mathrm{~kJ} \mathrm{~mol}^{-1}$. The BSSE corrected water adsorption energy using PBEsol in the QM/MM approach is therefore $-62.5 \mathrm{~kJ} \mathrm{~mol}^{-1}$, in excellent agreement with the periodic estimate extrapolated to infinite dilution.

On the $\mathrm{MgO}(100)$ surface, previous work has reported the lowest energy structure for a single adsorbed methanol molecule to have the alcohol group interacting through the molecule's $\mathrm{O}$ atom with an $\mathrm{Mg}_{5 \mathrm{c}}$ site while the $\mathrm{H}$ atom interacts with a surface basic $\mathrm{O}_{5 \mathrm{c}}$ site. ${ }^{42} \mathrm{We}$ have used this configuration to compare the periodic and QM/MM approaches. Table 2 shows that, at the PBEsol level, periodic and QM/MM calculations agree on the value of the adsorption energy for methanol to within $1 \mathrm{~kJ} \mathrm{~mol}^{-1}$. Both approaches also give the expected low energy geometry with the periodic calculation having a methanol $\mathrm{H}$ to surface $\mathrm{O}^{2-}$ ion $\left(\mathrm{CH}_{3} \mathrm{OH} \ldots \mathrm{O}_{5 \mathrm{c}}\right)$ distance of $1.570 \AA$ and a methanol oxygen atom to surface $\mathrm{Mg}^{2+}$ cation $\left(\mathrm{CH}_{3} \mathrm{O}(\mathrm{H}) \ldots \mathrm{Mg}_{5 \mathrm{c}}\right)$ distance of 
$2.184 \AA$. The QM/MM calculation favours the interaction with the basic $\mathrm{O}_{5 \mathrm{c}}$ site, giving $\mathrm{CH}_{3} \mathrm{OH} \ldots \mathrm{O}_{5 \mathrm{c}}=1.545 \AA$ and $\mathrm{CH}_{3} \mathrm{O}(\mathrm{H}) \ldots \mathrm{O}_{5 \mathrm{c}}=2.225 \AA$. Previous calculations by Branda et $a l .{ }^{43}$ on methanol on $\mathrm{MgO}$ using a simple cluster approach and the B3LYP hybrid functional gave a value of $-57 \mathrm{~kJ} \mathrm{~mol}^{-1}$ while periodic slab calculations with the PW91 functional yielded an estimate of $-49 \mathrm{~kJ} \mathrm{~mol}^{-1}$, which is significantly less favourable than the PBEsol values reported here. Campbell and co-workers have compiled a review of the experimentally measured heats of adsorption for small molecules on the surfaces of a range of oxides. ${ }^{44}$ The heat of adsorption of methanol to $\mathrm{MgO}(100)$ has been measured using equilibrium isotherms ${ }^{45}$ giving $\Delta \mathrm{H}_{\mathrm{ads}}=-72 \mathrm{~kJ} \mathrm{~mol}^{-1}$ while temperature programmed desorption measurements ${ }^{44}$ have been used to estimate $\Delta \mathrm{H}_{\mathrm{ads}}$ in the range 83.7 to $90.5 \mathrm{~kJ} \mathrm{~mol}^{-1}$, depending on surface coverage, with the higher value from the lowest coverages. Table 2 shows that all the DFT methods underestimate the experimental values except for the periodic PBEsol+D3 models which give a value of $E_{a d s}=-93 \mathrm{~kJ} \mathrm{~mol}^{-1}$, which is close to the low coverage end of the experimental estimates. This indicates that dispersion interactions are important for the description of adsorbate..surface interactions in this system. The dispersion interaction also shortens the distances between adsorbate and surface atoms giving, $\mathrm{CH}_{3} \mathrm{OH} \ldots \mathrm{O}_{5 \mathrm{c}}=1.544 \AA$ and $\mathrm{CH}_{3} \mathrm{O}(\mathrm{H}) \ldots \mathrm{Mg}_{5 \mathrm{c}}=2.163 \AA$ at the PBEsol+D3 level.

Experiments using $\mathrm{MgO}(100)$ produced by sputtering and annealing of thin films of $\mathrm{MgO}$ on the surface of $\operatorname{Mg}(0001)$ under ultra-high vacuum have been used to estimate the dissociated methanol population based on ion scattering spectroscopy (ISS). ${ }^{46}$ These experiments show a decrease in the population of surface methoxy species when defect densities in the thin film are reduced by annealing. In all of our calculations setting up of a dissociated methanol molecule with the methoxy anion and the hydroxyl group formed by proton transfer to the surface on neighbouring $\mathrm{Mg}_{5 \mathrm{c}}$ and $\mathrm{O}_{5 \mathrm{c}}$ sites always resulted in an optimised structure with the molecular species reformed. When the $\mathrm{H}^{+}$was shifted to a form a hydroxyl at the next nearest neighbour $\mathrm{O}_{5 \mathrm{c}}$ site a dissociated state was found to be stable but the adsorption energy relative to gas phase methanol was found to be $+35 \mathrm{~kJ} \mathrm{~mol}^{-1}$, even using the periodic PBEsol+D3 level of theory which consistently gives the lowest estimate for adsorption energies (Table 2). This finding suggests that the $\mathrm{MgO}(100)$ surface is not sufficiently basic to favour heterolytic dissociation of the alcohol group.

The periodic slab approach with the PBEsol functional gave a structure for the hydroxymethyl radical $\left(\bullet \mathrm{CH}_{2} \mathrm{OH}\right)$ analogous to the methanol adsorption mode. However, the calculated adsorption energy is only around half that of methanol and the $\mathrm{H}$ of the $\mathrm{OH}$ group does not 
interact as closely with the surface $\left(\bullet \mathrm{CH}_{2} \mathrm{OH} \ldots \mathrm{O}_{5 \mathrm{c}}=2.497 \AA\right.$ and $\bullet \mathrm{CH}_{2} \mathrm{O}(\mathrm{H}) \ldots \mathrm{Mg}_{5 \mathrm{c}}=2.174$ $\AA$ ). In the QM/MM calculated structure with the same functional, $\mathrm{H}^{+}$is abstracted from the hydroxymethyl radical on optimisation to form a surface adsorbed radical anion $\left(\bullet \mathrm{CH}_{2} \mathrm{O}^{-}\right)$and a surface hydroxyl group. The assignment of this species as a radical anion is confirmed by the Mulliken analysis from the QM/MM FHI-aims calculations which assigns a total charge to the $\mathrm{CH}_{2} \mathrm{O}$ species of $-0.38|e|$ with the $\mathrm{H}$ in the newly formed hydroxyl group having a Mulliken charge of $0.41|e|$. The deprotonation of the hydroxymethyl radical leads to a much more favourable calculated adsorption energy for the dissociated state than was seen for the molecular species $\left(E_{a d s}(\mathrm{PBEsol}, \mathrm{QM} / \mathrm{MM})=-81 \mathrm{~kJ} \mathrm{~mol}^{-1}\right)$, which was confirmed when the same structure was optimised using the periodic approach $\left(E_{a d s}(\right.$ PBEsol, periodic $)=-73 \mathrm{~kJ}$ $\mathrm{mol}^{-1}$ ). Figure 3 shows the optimised geometries and spin density for this structure calculated using the PBEsol functional under periodic boundary conditions and hybrid PBE0 within the QM/MM approach. At the PBEsol level, the $\bullet \mathrm{CH}_{2} \mathrm{O}^{-}$forms a hydrogen bond to the surface with a $\bullet \mathrm{CH}_{2} \mathrm{O}^{-} \ldots \mathrm{H}^{+}$distance of $1.406 \AA$; there is also a close interaction between the $\mathrm{O}$ of $\bullet \mathrm{CH}_{2} \mathrm{O}^{-}$ and an $\mathrm{Mg}_{5 \mathrm{c}}$ surface site at a separation of $2.101 \AA$. The spin density iso-surface also shows that the distribution of the unpaired electron in the radical anion is distorted toward the surface, with the spin centred on the $C$ atom polarised toward a surface $\operatorname{Mg}_{5 c}$ site $\left(C \ldots \operatorname{Mg}_{5 c}=2.796\right.$ A).

So it appears that, although the $\mathrm{MgO}(100)$ surface is not sufficiently basic to deprotonate the methanol product in the reaction it can easily abstract a proton from the hydroxymethyl radical formed by the homolytic cleavage of $\mathrm{C}-\mathrm{C}$ bonds in glycerol or hydroxyacetone.
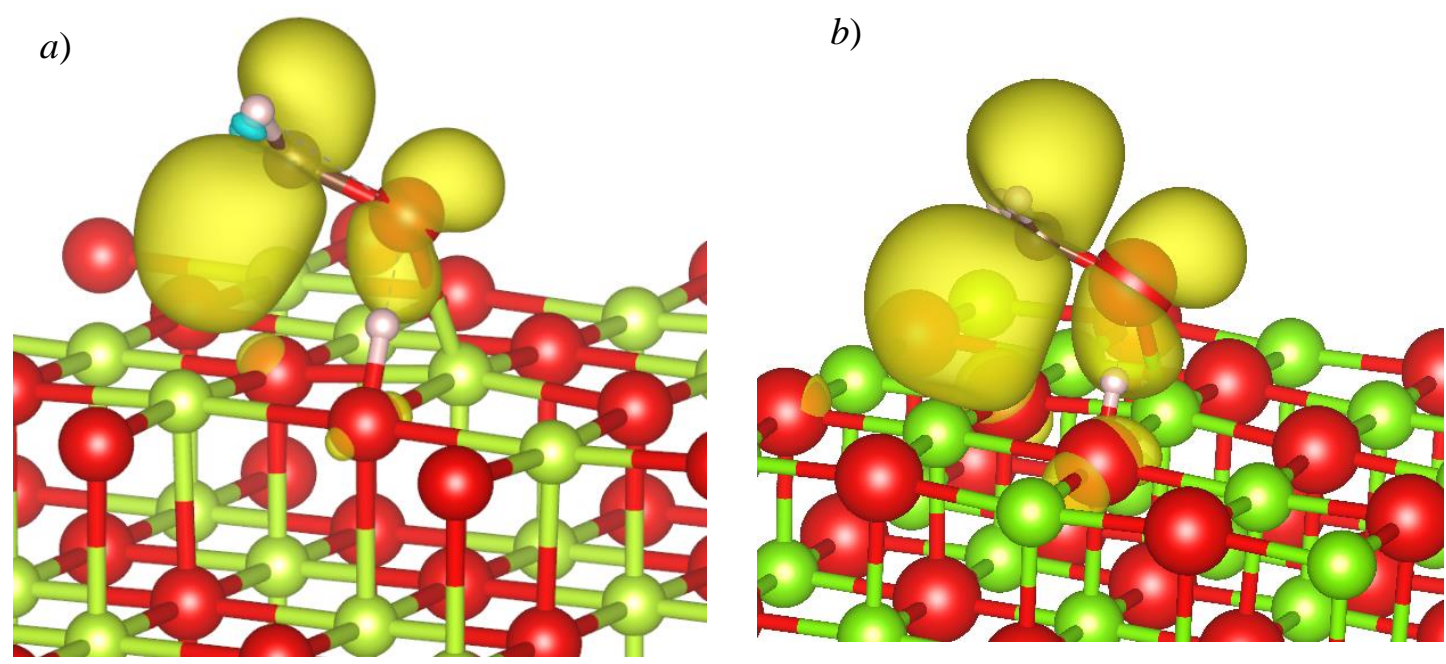

Figure 3: Optimised structures for the dissociated hydroxymethyl radical using $a$ ) periodic DFT (PBEsol) and $b$ ) QM/MM (PBE0). Atom colours; green: Mg, red: O, grey: C, white: H. Spin density isosurface shown at 0.005 e $\AA^{-3}$ level. 
In the periodic calculations, adsorption of ethylene glycol was tested with a single $\mathrm{OH}$ group interacting with the surface and with both $\mathrm{OH}$ groups orientated toward the surface. Table 2 reports the adsorption energies for the case with both alcohol groups toward the surface which was found to be more stable by around $30 \mathrm{~kJ} \mathrm{~mol}^{-1}$, for both PBEsol and PBEsol+D3.

Table 2: Adsorption energies for key molecules on $\mathrm{MgO}(100)$ comparing periodic and QM/MM approaches.

\begin{tabular}{|c|c|c|c|c|}
\hline Molecule & $\begin{array}{l}\text { PBEsol } \\
\text { (periodic) } / \mathrm{kJ} \mathrm{mol}^{-1}\end{array}$ & $\begin{array}{c}\text { PBEsol+D3 } \\
\text { (periodic) } \\
/ \mathrm{kJ} \mathrm{mol}^{-1}\end{array}$ & $\begin{array}{c}\text { PBEsol } \\
(\mathrm{QM} / \mathrm{MM}) \\
/ \mathrm{kJ} \mathrm{mol}^{-1}\end{array}$ & $\begin{array}{c}\text { PBE0 } \\
(\mathrm{QM} / \mathrm{MM}) \\
/ \mathrm{kJ} \mathrm{mol}^{-1}\end{array}$ \\
\hline water & -60 & -82 & -65 & -59 \\
\hline methanol & -61 & -93 & -60 & -52 \\
\hline$\cdot \mathrm{CH}_{2} \mathrm{OH}$ & -32 & -59 & ---- & ---- \\
\hline$\cdot \mathrm{CH}_{2} \mathrm{O}^{-} \ldots . \mathrm{H}^{+}$ & -73 & -105 & -81 & -57 \\
\hline ethylene glycol $1^{a}$ & -61 & -109 & -65 & -45 \\
\hline ethylene glycol $2^{b}$ & -90 & -136 & -89 & -63 \\
\hline
\end{tabular}

Note: $a$ ) ethylene glycol with an $\mathrm{OH}$ group interacting with the surface, $b$ ) ethylene glycol in a conformation with both $\mathrm{OH}$ groups interacting with the surface. In both cases the same gas phase reference conformation is used for calculation of the adsorption energy.

\section{Reaction Scheme}

\section{Periodic PBEsol+D3}

In the periodic calculations we have seen that the PBEsol+D3 approach can give a reasonable estimate for experimentally measured adsorption energies of water and methanol. So that the influence of the interaction between the intermediates and catalyst surface should be well represented with this methodology. We have therefore used this approach to map out the potential energy surface for the $\mathrm{H}$ transfer process by obtaining the adsorbed stable intermediate energy for a series of steps in the process, Scheme 3.

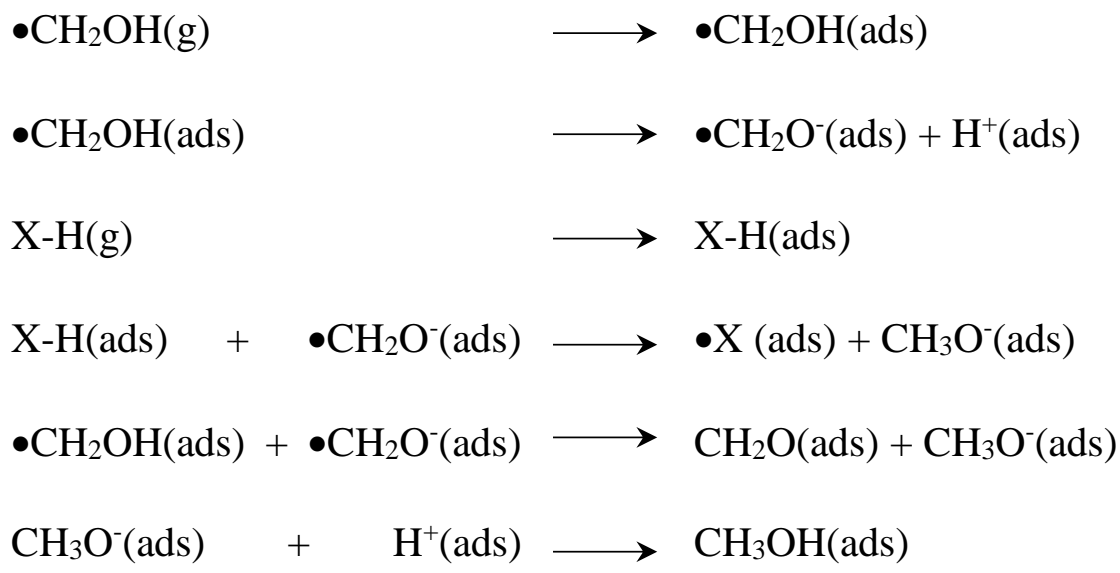


Scheme 3: Proposed reaction scheme for $\mathrm{H}$ transfer process on the $\mathrm{MgO}$ surface.

In the adsorption calculations presented in the previous section, the deprotonation of the hydroxymethyl radical has been found to occur readily. In steps (1) and (2) of Scheme 3, this

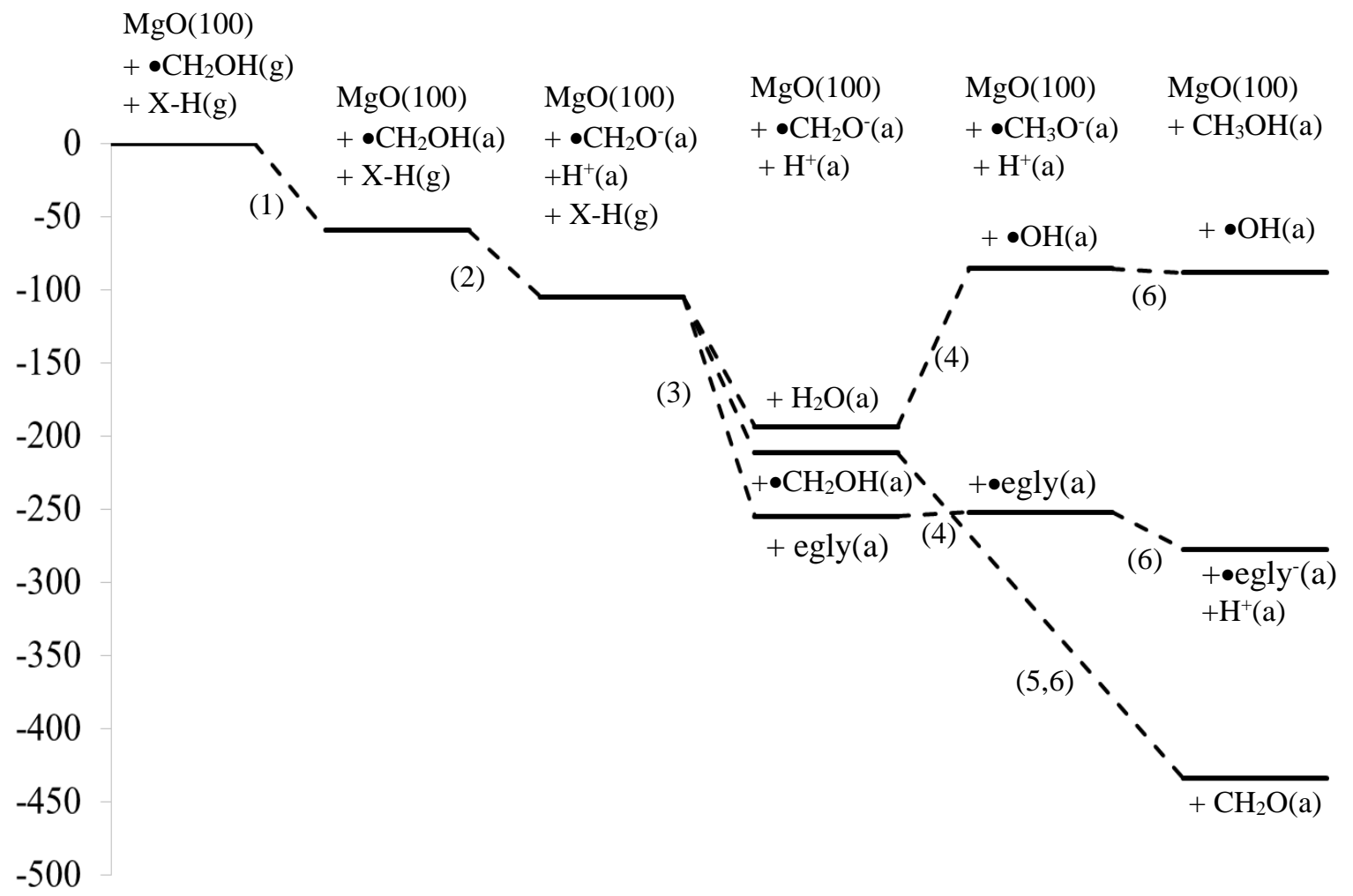

Figure 4: Calculated potential energy surface for the production of methanol from a hydroxymethyl radical following steps (1) - (6) in the proposed reaction sequence involving $\mathrm{H}$ abstraction from ethylene glycol. Energy values at the PBEsol+D3 level. From step (3) the species at the top of the figure are common to all structures with only differences in the $\mathrm{H}$ source used given on the individual levels. Abbreviations; (g) gas phase species, (a) adsorbed species, egly = ethylene glycol, $\mathrm{HOCH}_{2} \mathrm{CH}_{2} \mathrm{OH}$, •egly = carbon centred radical from ethylene glycol, $\mathrm{HO} \bullet \mathrm{CHCH}_{2} \mathrm{OH}, \bullet e g l{ }^{-}=$carbon centred radical anion from ethylene glycol, $-\mathrm{O} \bullet \mathrm{CHCH}_{2} \mathrm{OH}$.

is introduced as an additional part of the glycerol to methanol process. In the later steps the $\mathrm{H}$ transfer process involves the homolytic cleavage of the $\mathrm{X}-\mathrm{H}$ bond in another adsorbate $(\mathrm{X}-\mathrm{H}=$ water or ethylene glycol $(\mathrm{C}-\mathrm{H}))$ and the formation of a methoxy anion (step 4). We also consider the possibility of a disproportionation reaction involving the adsorption of a second hydroxymethyl radical which transfers a $\mathrm{H}$ atom to the hydroxymethyl anion surface species to produce formaldehyde and a surface methoxy anion (step 5). Finally, surface methoxy species can be protonated by surface hydroxyl groups to form methanol (step 6). Figure 4 shows the calculated potential energy landscape for these elementary steps at the PBEsol+D3 
level and Figure 5 shows the key intermediates considered and gives associated information on the interactions between adsorbates and the surface sites. The co-adsorption of water with the dissociated hydroxymethyl radical gives an effective adsorption energy for water of $-89 \mathrm{~kJ} \mathrm{~mol}^{-}$ ${ }^{1}, 7 \mathrm{~kJ} \mathrm{~mol}^{-1}$ more negative than found for water on the clean $\mathrm{MgO}(100)$ surface (Table 1).

a)

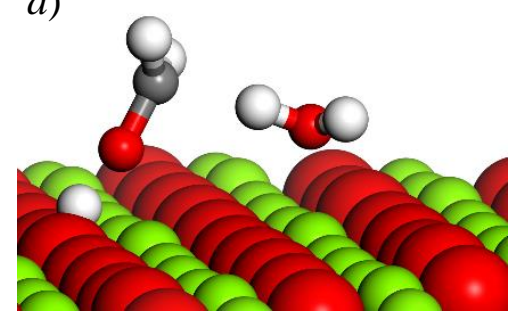

$\mathrm{O}_{5 \mathrm{c}} \mathrm{H} \ldots{ }^{-} \mathrm{O}\left(\bullet \mathrm{CH}_{2}\right)=1.538 \AA$

$\mathrm{Mg}_{5 \mathrm{c}} \ldots \mathrm{O} \mathrm{O}\left(\bullet \mathrm{CH}_{2}\right)=2.027 \AA$

$\mathrm{Mg}_{5 \mathrm{c}} \ldots \mathrm{OH}_{2}=2.103 \AA$

$\mathrm{HO}-\mathrm{H} \ldots \cdot \bullet \mathrm{CH}_{2} \mathrm{O}=1.845 \AA$

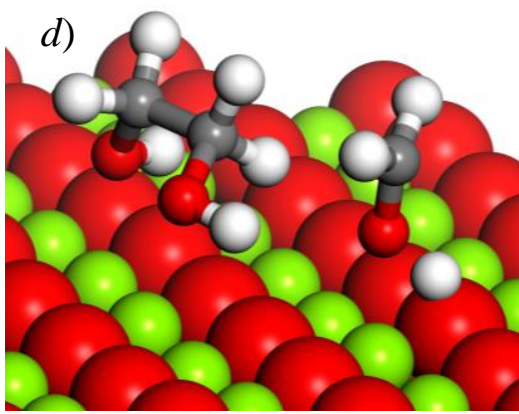

$\mathrm{O}_{5 \mathrm{c}} \ldots \mathrm{HO}\left(\mathrm{CH}_{2}\right) \mathrm{CH}_{2} \mathrm{OH}$

$$
=2.187 \AA, 1.977 \AA
$$

$\mathrm{Mg}_{5 \mathrm{c}} \ldots \mathrm{O}(\mathrm{H}) \mathrm{CH}_{2} \mathrm{CH}_{2} \mathrm{OH}$

$$
=2.104 \AA, 2.161 \AA
$$

$\mathrm{O}_{5 \mathrm{c}} \mathrm{H} . . . \mathrm{O}\left(\bullet \mathrm{CH}_{2}\right)=1.493 \AA$

$\mathrm{Mg}_{5 \mathrm{c}} \ldots \mathrm{O}\left(\bullet \mathrm{CH}_{2}\right)=2.042 \AA$

g)

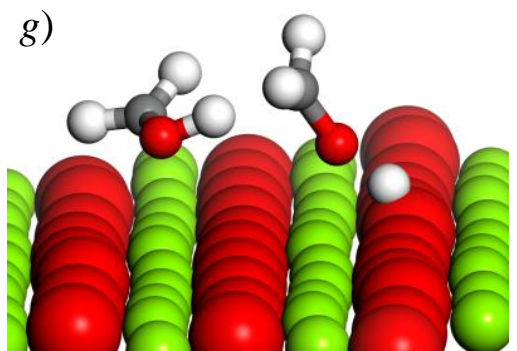

$\mathrm{O}_{5 \mathrm{c}} \mathrm{H} \ldots \mathrm{O}\left(\bullet \mathrm{CH}_{2}\right)=1.579 \AA$

$\mathrm{Mg}_{5 \mathrm{c}} \ldots \mathrm{O}\left(\bullet \mathrm{CH}_{2}\right)=2.040 \AA$

$\mathrm{Mg}_{5 \mathrm{c}} \ldots \mathrm{OH}\left(\bullet \mathrm{CH}_{2}\right)=2.227 \AA$

$\mathrm{Mg}_{5 \mathrm{c}} \ldots \bullet \mathrm{CH}_{2} \mathrm{OH}=2.764 \AA$

$\bullet \mathrm{CH}_{2} \mathrm{OH} \ldots \bullet \mathrm{CH}_{2} \mathrm{O}^{-}=1.644 \AA$

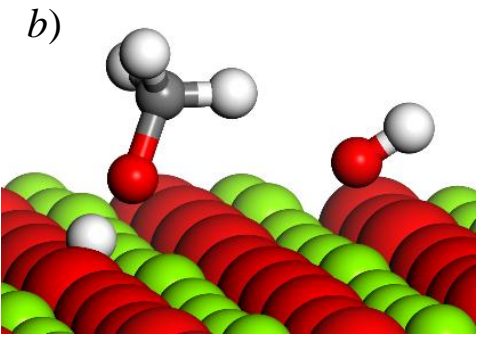

$\mathrm{O}_{5 \mathrm{c}} \mathrm{H} \ldots \mathrm{O}\left(\mathrm{CH}_{3}\right)=1.445 \AA$

$\mathrm{Mg}_{5 \mathrm{c}} \ldots \mathrm{O}\left(\mathrm{CH}_{3}\right)=2.000 \AA$

$\mathrm{Mg}_{5 \mathrm{c}} \ldots \bullet \mathrm{OH} \quad=2.039 \AA$

$-\mathrm{O}\left(\mathrm{CH}_{2}\right)-\mathrm{H} . . . \bullet \mathrm{OH}=2.638 \AA$

e)

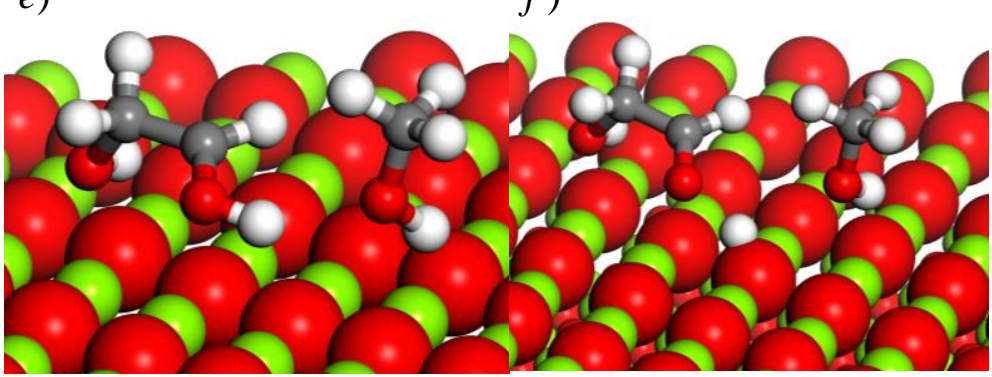

$\mathrm{O}_{5 \mathrm{c}} \ldots \mathrm{HOCH}_{2}-\bullet \mathrm{R}_{1}=2.230 \AA$

$\mathrm{Mg}_{5 \text { c.. }} \mathrm{O}(\mathrm{H}) \mathrm{CH}_{2}-\bullet \mathrm{R}_{1}=2.143 \AA$

$\mathrm{Mg}_{5 \mathrm{c} .} . \mathrm{O}(\mathrm{H}) \bullet \mathrm{CH}-\mathrm{R}_{2}=2.260 \AA$

$\mathrm{O}_{5 \mathrm{c}} \ldots \mathrm{HO} \bullet \mathrm{CH}-\mathrm{R}_{2}=1.860 \AA$

$\mathrm{CH}_{3} \mathrm{O}(\mathrm{H}) . . \mathrm{HO} \bullet \mathrm{CH}-\mathrm{R}_{2}=2.075 \AA$

$\mathrm{CH}_{3} \mathrm{O} . . \mathrm{H}-\mathrm{O}_{5 \mathrm{c}}=1.239 \AA$

$\mathrm{CH}_{3} \mathrm{OH} . . \mathrm{O}_{5 \mathrm{c}}=1.204 \AA$

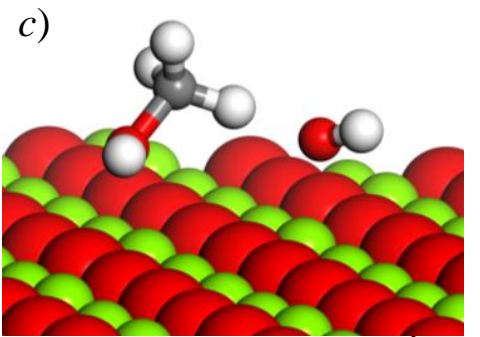

$\mathrm{O}_{5 \mathrm{c}} \ldots \mathrm{HO}\left(\mathrm{CH}_{3}\right)=2.319 \AA$

$\mathrm{Mg}_{5 \mathrm{c}} \ldots \mathrm{OH}\left(\mathrm{CH}_{3}\right)=2.130 \AA$

$\mathrm{Mg}_{5 \mathrm{c}} \ldots \bullet \mathrm{OH} \quad=2.028 \AA$

$\mathrm{HO}\left(\mathrm{CH}_{2}\right)-\mathrm{H} \ldots \bullet \mathrm{OH}=1.837 \AA$

f)

$\mathrm{O}_{5 \mathrm{c}} \ldots \mathrm{HOCH}_{2}-\bullet \mathrm{R}_{3}=2.337 \AA$

$\mathrm{Mg}_{5 \mathrm{c}} \ldots \mathrm{OH}\left(\mathrm{CH}_{2}\right)-\bullet \mathrm{R}_{3}=2.141 \AA$

$\mathrm{Mg}_{5 \mathrm{c}} \ldots \mathrm{O}(\bullet \mathrm{CH})-\mathrm{R}_{2}=2.058 \AA$

$\mathrm{O}_{5 \mathrm{c}} \mathrm{H} .{ }^{-} \mathrm{O}(\cdot \mathrm{CH})-\mathrm{R}_{2}=1.546 \AA$

$\mathrm{O}_{5 \mathrm{c}}-\mathrm{H}=1.040 \AA$

$\mathrm{CH}_{3} \mathrm{OH} \ldots \mathrm{O}_{5 \mathrm{c}}=1.719 \AA$

$\mathrm{CH}_{3} \mathrm{O}(\mathrm{H}) . . \mathrm{Mg}_{5 \mathrm{c}}=2.128 \AA$

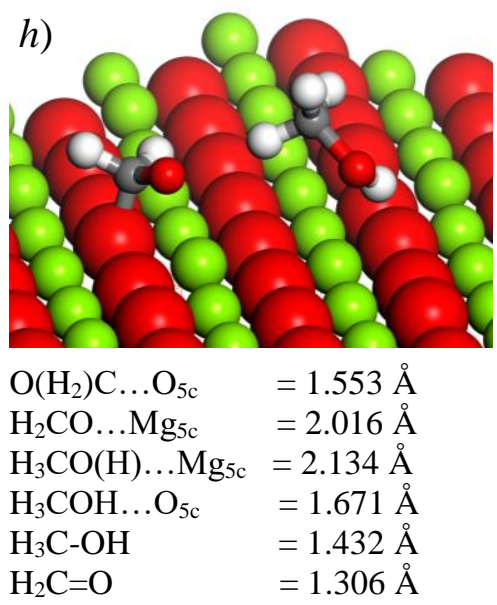


Figure 5: Structures from $\mathrm{H}$ transfer process reactions for the conversion of a surface adsorbed hydroxymethyl radical anion to methanol. $a$ )-c) Water as $\mathrm{H}$ source, $b$ ) ethylene glycol as $\mathrm{H}$ source $c$ ) disproportionation reaction with second hydroxymethyl radical. Atom colours; green: $\mathrm{Mg}$, red: $\mathrm{O}$, grey: $\mathrm{C}$, white: $\mathrm{H}$. $\mathrm{R}_{1}=-\mathrm{CHOH}, \mathrm{R}_{2}=-\mathrm{CH}_{2} \mathrm{OH}$, $\mathrm{R}_{3}=-\mathrm{CH}_{2} \mathrm{O}^{-}$.

Figure $5 a$ shows that the water molecule interacts through the $\mathrm{O}$ atom co-ordinating to a surface $\mathrm{Mg}_{5 \mathrm{c}}$ site in much the same way as for the clean surface, but the water molecule in this case also hydrogen bonds to the carbon of the hydroxymethyl radical anion with an interaction distance of $1.845 \AA$. Transferring the $\mathrm{H}$ atom from water to the hydroxymethyl radical anion results in formation of the methoxy anion precursor to methanol but at a cost of $108 \mathrm{~kJ} \mathrm{~mol}^{-1}$. The resulting hydroxyl radical interacts with surface cations on the $\mathrm{MgO}(100)$ surface; the closest contact between this species and the surface is an $\mathrm{Mg}_{5 \mathrm{c}} \ldots \bullet \mathrm{OH}$ interaction at a separation of $2.039 \AA$, (Figure $5 b$ ), comparable to that of the water $\mathrm{Mg}_{5 \mathrm{c}} \ldots \mathrm{OH}_{2}$ but the $\mathrm{H}$ atom of $\bullet \mathrm{OH}$ is more than $2.5 \AA$ from the nearest $\mathrm{O}_{5 \mathrm{c}}$ site. .

When ethylene glycol is used as the $\mathrm{H}$ atom donor for the reaction step (3), the adsorption of ethylene glycol in the presence of the dissociated hydroxymethyl radical anion is favourable with an effective adsorption energy of $-150 \mathrm{~kJ} \mathrm{~mol}^{-1}$. This is more negative than found for ethylene glycol on the clean $\mathrm{MgO}(100)$ surface using the same methodology, $E_{\text {ads }}=-136 \mathrm{~kJ}$ $\mathrm{mol}^{-1}$ (Table 2). In contrast to the case of water, transfer of $\mathrm{H}$ from a $\mathrm{C}-\mathrm{H}$ bond in ethylene glycol to form a methoxy intermediate occurs with only a small change of the overall system energy $\left(+3 \mathrm{~kJ} \mathrm{~mol}^{-1}\right)$.

The geometry data in Figure $5 e$ also shows that, for this "methoxy" intermediate step, the surface $\mathrm{O}_{5 \mathrm{c}}-\mathrm{H}$ bond is activated and only marginally shorter than the $\mathrm{CH}_{3} \mathrm{O}^{-} \ldots \mathrm{H}$ distance. The final step to produce adsorbed methanol in this case is accompanied by a deprotonation of the carbon centred radical produced from ethylene glycol, again indicating that the $\mathrm{MgO}(100)$ surface is sufficiently basic to deprotonate radical alcohols. Overall, the production of a secondary carbon radical and its deprotonation on the surface leads to an energetically favourable production of methanol.

Finally we consider the disproportionation route over the $\mathrm{MgO}(100)$ surface. The calculated adsorption energy for the second hydroxymethyl radical is $-107 \mathrm{~kJ} \mathrm{~mol}^{-1}$ which is almost the same as found for the dissociated radical on the clean $\mathrm{MgO}(100)$ at the same level of theory ( $E_{a d s}=-105 \mathrm{~kJ} \mathrm{~mol}^{-1}$, Table 2). However, in Figure $5 g$ it can be seen that the second radical adsorbs without dissociation with the plane of the molecule parallel to the surface. In this 
configuration, both the $\mathrm{O}$ atom of the radical is close to a $\mathrm{Mg}_{5 \mathrm{c}}$ site and there is a short hydrogen bonding interaction to the carbon centre of the radical anion, ${ }^{-} \mathrm{CH}_{2} \mathrm{OH} . . \mathrm{C}\left(\mathrm{H}_{2}\right) \mathrm{O}^{-}(1.644 \AA)$. After transferring the $\mathrm{H}$ atom to form a methyl group, there is no intermediate structure with a methoxy species since the proton from the surface hydroxyl group is immediately transferred to form the product methanol. The resulting formaldehyde molecule is strongly bound to the surface through an $\mathrm{O}_{5 \mathrm{c}} \ldots \mathrm{C}\left(\mathrm{H}_{2}\right)=\mathrm{O}$ interaction $\left(1.553 \AA\right.$ ). Even so, comparison of the $\mathrm{H}_{3} \mathrm{C}-\mathrm{OH}$ $(1.432 \AA)$ and $\mathrm{CH}_{2}=\mathrm{O}(1.306 \AA)$ bond lengths in Figure $5 h$ demonstrates that the double bond in formaldehyde has formed. Figure 4 shows that this disproportionation reaction is considerably more energetically favourable than the alternatives leading to radical co-products since it represents a termination of a radical reaction sequence.

\section{QM/MM PBEO}

Figure 6 shows the calculated potential energy surface derived from the PBE0 hybrid functional energy calculations at the PBEsol optimised structures using the ChemShell QM/MM approach. Structures were both constructed independently and adapted from the PBEsol periodic optimisations reported in the previous section and the diagram summarises the lowest energy configurations found for each point on the PES. In this case we were unable to locate an optimised structure with the hydroxymethyl radical molecularly adsorbed and so the first step on the PES is the adsorption and deprotonation (1,2 in Scheme 3) to produce the anionic radical $\bullet \mathrm{CH}_{2} \mathrm{O}^{-}$adsorbed on the $\mathrm{MgO}(100)$ surface. Step 3 in Scheme 3 is the co-adsorption of water, ethylene glycol or a second hydroxymethyl radical. As in the case of the PBEsol+D3 periodic calculations, water shows the lowest reduction in energy on adsorption with $\bullet \mathrm{CH}_{2} \mathrm{O}^{-}$ (ads) $+\mathrm{H}^{+}$(ads) on the surface with an effective adsorption energy of $-54 \mathrm{~kJ} \mathrm{~mol}^{-1}$ which is comparable to the $-59 \mathrm{~kJ} \mathrm{~mol}^{-1}$ found for water on the clean surface (Table 2). The adsorption of ethylene glycol in the presence of the hydroxymethyl radical has an estimated adsorption energy of $-75 \mathrm{~kJ} \mathrm{~mol}^{-1}$ which is some $12 \mathrm{~kJ} \mathrm{~mol}^{-1}$ more favourable than for ethylene glycol on the clean surface at the same level of theory. For the disproportionation reaction, the adsorption of a second hydroxymethyl radical in a molecular form gives $E_{a d s}=-76 \mathrm{~kJ} \mathrm{~mol}^{-1}$; in the optimised adsorption geometry the $\bullet \mathrm{CH}_{2} \mathrm{OH}$ species has a close interaction with the carbon of the dissociated radical on the surface $\left(\bullet \mathrm{CH}_{2} \mathrm{OH} \ldots \bullet \mathrm{CH}_{2} \mathrm{O}^{-}=1.647 \AA\right)$. We do not have an estimate for the adsorption of $\bullet \mathrm{CH}_{2} \mathrm{OH}$ in molecular form on the clean surface but, at the PBE0 level, the dissociated form has an adsorption energy $19 \mathrm{~kJ} \mathrm{~mol}^{-1}$ higher (Table 2), indicating that co-adsorption is more favourable than adsorption of the second radical elsewhere on the 


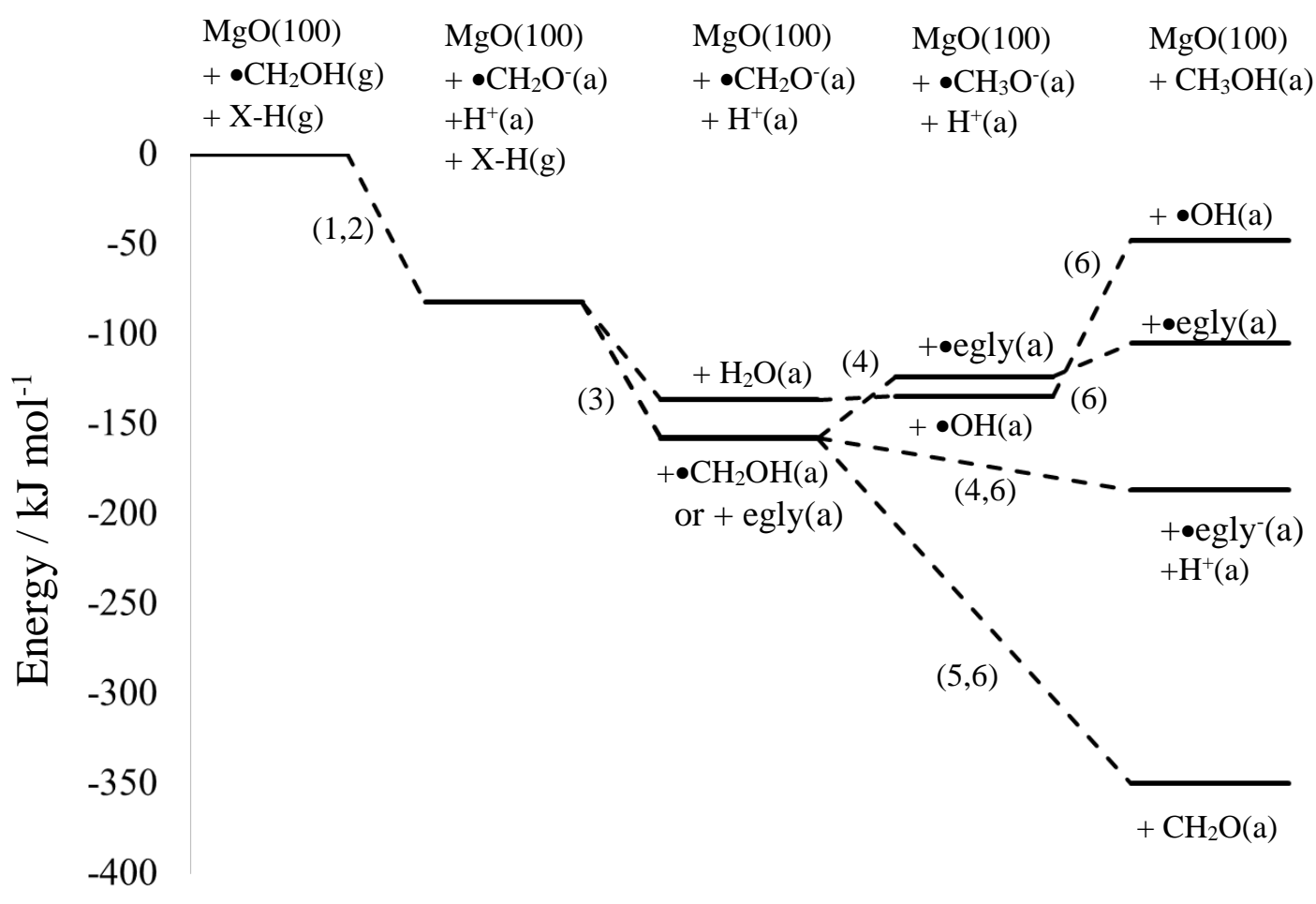

Figure 6. Calculated potential energy surface for the production of methanol from a hydroxymethyl radical following steps (1) - (6) in the proposed reaction sequence. Energy values at the PBE0 level using the ChemShell QM/MM models. From step (3) the species at the top of the figure are common to all structures with only differences in the $\mathrm{H}$ source used given on the individual levels. Abbreviations; (g) gas phase species, (a) adsorbed species, egly = ethylene glycol, $\mathrm{HOCH}_{2} \mathrm{CH}_{2} \mathrm{OH}$, $\bullet$ egly = carbon centred radical from ethylene glycol, $\mathrm{HO} \bullet \mathrm{CHCH}_{2} \mathrm{OH}$, $\bullet$ egly ${ }^{-}=$carbon centred radical anion from ethylene glycol, ${ }^{-} \mathrm{O} \bullet \mathrm{CHCH}_{2} \mathrm{OH}$.

surface. The adsorption of ethylene glycol in the presence of the dissociated hydroxymethyl radical gives an adsorption energy only $1 \mathrm{~kJ} \mathrm{~mol}^{-1}$ higher than that calculated for the second - $\mathrm{CH}_{2} \mathrm{OH}$ species, so that on the scale of Figure 6 the two states cannot be distinguished. Hydrogen transfer from a C-H bond of ethylene glycol to form a surface bound surface methoxy anion and then to form adsorbed methanol actually leads to an increase in the system energy. However, on comparison of the structure with the periodic results we noted that the ethylene glycol radical was in neutral form whereas in the periodic calculations we found that the radical deprotonated. Transferring the structure from the periodic system to QM/MM showed that the deprotonation of the ethylene glycol radical also gave a lower energy configuration at the PBE0 level and so a second state for methanol production with a coadsorbed ethylene glycol radical anion and surface proton is reported in Figure 6 which shows a negative overall reaction energy. Once again, the most favourable reaction process for 
methanol production is found for the disproportionation reaction with the two surface bound hydroxymethyl radicals to produces methanol and formaldehyde.

Table 3 makes a comparison of the energy changes for the hydrogen transfer process based on water, ethylene glycol or disproportionation, steps $4-6$ for the proposed reaction scheme (Scheme 3), using the PBEsol+D3, PBE0 and compares these with BDE changes for Scheme 2 , which gives the energy balance for the overall reaction based on the PBE0 values from Table 1. In the case of water, the BDE estimates of the reaction energy, which do not take account of surface adsorption, show very similar reaction energies for the process taking place on the surface. However, for ethylene glycol the low energy of the radical product on deprotonation by the $\mathrm{O}_{5 \mathrm{c}}$ base site gives a considerably more negative reaction energy. This suggests a role for the basic oxide as a stabiliser of the side product from methanol formation.

Table 3: Calculated $\mathrm{H}$-transfer energies (steps 4,6 or steps 5,6, Scheme 3) for the various $\mathrm{H}$ sources, to form $\mathrm{CH}_{3} \mathrm{OH}($ ads $)$ from $\bullet \mathrm{CH}_{2} \mathrm{O}^{-}(\mathrm{ads})$.

\begin{tabular}{|c|c|c|c|}
\hline Molecule/bond & $\begin{array}{c}\text { PBEsol+D3 } \\
\text { (periodic) } \\
/ \mathrm{kJ} \mathrm{mol}^{-1}\end{array}$ & $\begin{array}{c}\text { PBE0 } \\
(\mathrm{QM} / \mathrm{MM}) \\
/ \mathrm{kJ} \mathrm{mol}^{-1}\end{array}$ & $\begin{array}{c}\triangle \mathrm{BDE}, \mathrm{PBE} 0 \\
(\mathrm{QM}) \\
/ \mathrm{kJ} \mathrm{mol}^{-1}\end{array}$ \\
\hline water $\mathrm{HO}-\mathrm{H}$ & 105 & 89 & 94 \\
\hline e-glycol ${ }^{a} \mathrm{C}-\mathrm{H}$ & ---- & 19 & -4 \\
\hline e-glycol ${ }^{b} \mathrm{C}-\mathrm{H}$ & -23 & -63 & -4 \\
\hline $\mathrm{CH}_{2} \mathrm{O}-\mathrm{H}$ & -223 & -192 & -254 \\
\hline
\end{tabular}

Notes: $a$ ) End point with neutral ethylene glycol radical, $b$ ) end point with deprotonation of ethylene glycol radical.

\section{Experimental follow-up}

The calculations presented in this work concentrate on the $\mathrm{MgO}(100)$ surface and we have also taken a simplified form of the overall reaction scheme in which the hydroxymethyl radical is generated straight from glycerol or its dehydration product hydroxyacetone. Even so, the calculations suggest several key points. Firstly, the use of water as an $\mathrm{H}$ donor in the final step of methanol production is energetically unfavourable and secondly the disproportionation reaction provides the lowest energy route to methanol. Table 4 gives some selectivity and conversion data for $\mathrm{MgO}$ catalysts calcined at various temperatures. The conversion has been kept low to limit secondary reactions. We note that the simplified scheme (Scheme 1) is able to account for $70.8 \%$ of products for the $\mathrm{MgO}_{\text {(4) }}$ (450) catalysts and $61.2 \%$ of products for the MgO_(750) material. Table S2 gives a list of all observed products which shows that the remaining products are either unidentified or are clearly products from secondary reactions. From the full list of products, we have estimated the hydrogen balance for the reaction without 
the inclusion of any $\mathrm{H}$ derived from solvent water to be $100.6 \%$, suggesting that water need not be involved in the radical mechanism.

In previous work and in Table S2 we have not quantified formaldehyde, but in light of the simulation data and other literature which qualitatively indicates that it can be stable under similar conditions, ${ }^{47-50}$ we have introduced an additional analysis method to test for its formation. The formation of formaldehyde in these reactions was tested through use of a LpDNPH cartridge. The LpDNPH cartridges contain high purity silica coated with 2,4dinitrophenylhydrazine, which forms hydrazone derivatives upon contact with carbonyl species. After the reaction, washing the cartridge in acetonitrile solubilises these derivatives, which can subsequently be quantified by HPLC. For this test a standard reaction was conducted over an $\mathrm{MgO}$ catalyst, the reactivity of which has previously been examined extensively. ${ }^{11}$ The LpDNPH cartridge was placed between the reactor after catalyst bed but before the cold trap to ensure interaction with all reaction products was achieved. By following this procedure and comparing the results against a calibration standard, we were able to confirm that formaldehyde is produced during the reaction; the formaldehyde-hydrazone derivative was clearly observed in the post reaction effluent. Accurate quantification of the formaldehyde produced in such reactions is challenging, particularly under the reaction conditions used for these experiments. In addition to the formation of the hydrazone derivative, the esterification reaction also leads to the formation of water and given that the reaction is run with a $50 \mathrm{wt} . \%$ glycerol in water feed, the quantity of additional water produced may have a significant impact on the relative concentration of the products in the cold trap. We therefore can only qualitatively confirm that formaldehyde is produced in significant quantities in these reactions at this stage. Further optimisation of the methodology will be conducted in order to accurately quantify the formaldehyde produced going forward.

Table 4: Experimental selectivity data for glycerol reactions over $\mathrm{MgO}$ catalysts at low conversion.

\begin{tabular}{|c|c|c|c|}
\hline \multirow{2}{*}{ product } & \multicolumn{3}{|c|}{ Catalyst material $^{a}$} \\
\hline & $\begin{array}{c}\mathrm{MgO}_{\bar{C}}(450) \\
\text { Sel }^{\circ} / \%\end{array}$ & $\begin{array}{c}\mathrm{MgO}(650) \\
\text { Sel }^{b} / \%\end{array}$ & $\begin{array}{c}\mathrm{MgO}_{\bar{b}}(750) \\
\text { Sel }^{\prime} / \%\end{array}$ \\
\hline acetaldehyde, $\mathbf{1 0}$ & 7.2 & 7.0 & 6.2 \\
\hline acrolein, 2 & 13.8 & 12.6 & 11.1 \\
\hline methanol, 7 & 8.6 & 8.1 & 8.0 \\
\hline ethanol, 9 & 0.3 & 0.3 & 0.3 \\
\hline hydroxyacetone, 3 & 26.9 & 26.0 & 22.2 \\
\hline ethylene glycol, $\mathbf{8}$ & 14.0 & 14.5 & 13.4 \\
\hline Glycerol conversion / \% & 8 & 5 & 7 \\
\hline
\end{tabular}




\begin{tabular}{cccc} 
Carbon balance $/ \%$ & 105 & 102 & 100 \\
$\mathrm{MeOH}$ S.T.Y. $/ \mathrm{g}_{\mathrm{MeOH} ~} \mathrm{~h}^{-1} \mathrm{~g}_{\mathrm{cat}}{ }^{-1}$ & 21 & 32 & 32 \\
\hline
\end{tabular}

Notes: $a)$ Number in brackets refers to the temperature $\left({ }^{\circ} \mathrm{C}\right)$ of the calcination step in the catalyst preparation. $b$ ) Selectivity defined in terms of moles of carbon in products detected, see equation $\mathrm{S} 9$.

\section{Summary and Conclusions}

In this contribution we have used DFT calculations both with periodic boundary and with an embedded QM/MM approach to study the reaction of glycerol over the $\mathrm{MgO}(100)$ surface. We find that alcohol groups at $\mathrm{C}$-centred radicals are deprotonated by the weak $\mathrm{O}_{5 \mathrm{c}}$ base sites on the surface, whereas alcohol groups of normal alcohols are not, which may actually be advantageous to catalysis as the methoxy anion produced on $\mathrm{H}$ atom transfer to the hydroxyl methyl radical anion will be readily protonated and desorbed from the surface as methanol.

In addition, we have shown how periodic and QM/MM approaches can be used in unison to arrive at a consistent model of surface processes. Here we have taken advantage of the availability of hybrid functionals in the QM/MM approach which were shown to give a better representation of the homolytic bond dissociation processes central to this catalysis. In future we will explore further the use of post Hartree Fock methods in elaborating the energetics of surface mediated radical reactions.

\section{Acknowledgements}

We would like to thank the EPSRC for funding this work (Grant reference codes: EP/P033695/1 and EP/L027240/1). Via our membership of the UK's HEC Materials Chemistry Consortium, which is funded by EPSRC (EP/L000202, EP/R029431), this work used the ARCHER UK National Supercomputing Service (http://www.archer.ac.uk) and the UK Materials and Molecular Modelling Hub for computational resources, MMM Hub, which is partially funded by EPSRC (EP/P020194).

Data in support of this paper is available from DOI: awaiting DOI.

\section{References}

1E. Lotero, Y. Liu, D. E. Lopez, K. Suwannakarn, D. A. Bruce and J. G. Goodwin, Synthesis of Biodiesel via Acid Catalysis, Ind. Eng. Chem. Res., 2005, 44, 5353-5363.

2C. S. K. Lin, L. A. Pfaltzgraff, L. Herrero-Davila, E. B. Mubofu, S. Abderrahim, J. H. Clark, A. A. Koutinas, N. Kopsahelis, K. Stamatelatou, F. Dickson, S. Thankappan, Z. Mohamed, R. Brocklesby and R. Luque, Food waste as a valuable resource for the production of chemicals, materials and fuels. Current situation and global perspective, Energy Environ. Sci., 2013, 6, 426.

3 M. Pagliaro, R. Ciriminna, H. Kimura, M. Rossi and C. Della Pina, From Glycerol to Value-Added Products, Angew. Chem. Int. Ed., 2007, 46, 4434-4440. 
4U. Nda-Umar, I. Ramli, Y. Taufiq-Yap and E. Muhamad, An Overview of Recent Research in the Conversion of Glycerol into Biofuels, Fuel Additives and other Bio-Based Chemicals, Catalysts, 2018, 9, 15.

5R. A. Sheldon, Green and sustainable manufacture of chemicals from biomass: state of the art, Green Chem, 2014, 16, 950-963.

6B. Katryniok, S. Paul, V. Bellière-Baca, P. Rey and F. Dumeignil, Glycerol dehydration to acrolein in the context of new uses of glycerol, Green Chem., 2010, 12, 2079.

7C.-H. (Clayton) Zhou, J. N. Beltramini, Y.-X. Fan and G. Q. (Max) Lu, Chemoselective catalytic conversion of glycerol as a biorenewable source to valuable commodity chemicals, Chem Soc Rev, 2008, 37, 527-549.

8 A. G. Adeniyi and J. O. Ighalo, A review of steam reforming of glycerol, Chem. Pap., 2019, 73, 2619-2635.

9M. H. Haider, N. F. Dummer, D. W. Knight, R. L. Jenkins, M. Howard, J. Moulijn, S. H. Taylor and G. J. Hutchings, Efficient green methanol synthesis from glycerol, Nat. Chem., 2015, 7, 1028-1032.

10 P. J. Smith, L. Smith, N. F. Dummer, M. Douthwaite, D. J. Willock, M. Howard, D. W. Knight, S. H. Taylor and G. J. Hutchings, Investigating the Influence of Reaction Conditions and the Properties of Ceria for the Valorisation of Glycerol, Energies, 2019, 12, 1359.

11 L. R. Smith, P. J. Smith, K. S. Mugford, M. Douthwaite, N. F. Dummer, D. J.

Willock, M. Howard, D. W. Knight, S. H. Taylor and G. J. Hutchings, New insights for the valorisation of glycerol over MgO catalysts in the gas-phase, Catal. Sci. Technol., 2019, 9, 1464-1475.

12 C. Chizallet, G. Costentin, M. Che, F. Delbecq and P. Sautet, Revisiting Acidobasicity of the MgO Surface by Periodic Density Functional Theory Calculations: Role of Surface Topology and Ion Coordination on Water Dissociation, J. Phys. Chem. B, 2006, 110, 15878-15886.

13 D. Cornu, H. Guesmi, J.-M. Krafft and H. Lauron-Pernot, Lewis Acido-Basic Interactions between $\mathrm{CO}_{2}$ and $\mathrm{MgO}$ Surface: DFT and DRIFT Approaches, J. Phys. Chem. C, 2012, 116, 6645-6654.

14 A. J. Logsdail, C. A. Downing, T. W. Keal, P. Sherwood, A. A. Sokol and C. R. A. Catlow, Modelling the chemistry of Mn-doped MgO for bulk and (100) surfaces, Phys. Chem. Chem. Phys., 2016, 18, 28648-28660.

15 K. M. Neyman, C. Inntam, V. A. Nasluzov, R. Kosarev and N. Rösch, Adsorption of d-metal atoms on the regular $\mathrm{MgO}(001)$ surface: Density functional study of cluster models embedded in an elastic polarizable environment, Appl. Phys. A, 2004, 78, 823-828.

16 K. M. Neyman, C. Inntam, L. V. Moskaleva and N. Rösch, Density Functional Embedded Cluster Study of $\mathrm{Cu}_{4}, \mathrm{Ag}_{4}$ and $\mathrm{Au}_{4}$ Species Interacting with Oxygen Vacancies on the MgO(001) Surface, Chem. - Eur. J., 2007, 13, 277-286.

17 A. D. Boese and J. Sauer, Accurate adsorption energies of small molecules on oxide surfaces: CO-MgO(001), Phys. Chem. Chem. Phys., 2013, 15, 16481.

18 S. Sicolo and J. Sauer, Interaction of CO with Electron-Rich Defects on $\mathrm{MgO}(100), J$. Phys. Chem. C, 2013, 117, 8365-8373.

19 C. A. Downing, A. A. Sokol and C. R. A. Catlow, The reactivity of $\mathrm{CO}_{2}$ and $\mathrm{H}_{2}$ at trapped electron sites at an oxide surface, Phys Chem Chem Phys, 2014, 16, 21153-21156.

20 G. Kresse and J. Hafner, Ab initio molecular dynamics for liquid metals, Phys. Rev. B, 1993, 47, 558-561.

21 G. Kresse and D. Joubert, From ultrasoft pseudopotentials to the projector augmentedwave method, Phys. Rev. B, 1999, 59, 1758-1775. 
22 J. P. Perdew, A. Ruzsinszky, G. I. Csonka, O. A. Vydrov, G. E. Scuseria, L. A. Constantin, X. Zhou and K. Burke, Restoring the Density-Gradient Expansion for Exchange in Solids and Surfaces, Phys. Rev. Lett., 2008, 100, 136406.

23 S. Grimme, J. Antony, S. Ehrlich and H. Krieg, A consistent and accurate ab initio parametrization of density functional dispersion correction (DFT-D) for the 94 elements H$\mathrm{Pu}$, J. Chem. Phys., 2010, 132, 154104.

24 R. M. Hazen, Effects of temperature and pressure on the cell dimension and X-ray temperature factors of periclase, Am. Mineral., 1976, 61, 266-271.

25 Z. P. Chang and G. R. Barsch, Pressure dependence of the elastic constants of singlecrystalline magnesium oxide, J. Geophys. Res., 1969, 74, 3291-3294.

26 P. Broqvist, H. Grönbeck and I. Panas, Surface properties of alkaline earth metal oxides, Surf. Sci., 2004, 554, 262-271.

27 S. C. Parker, N. H. de Leeuw and S. E. Redfern, Atomistic simulation of oxide surfaces and their reactivity with water, Faraday Discuss., 1999, 114, 381-393.

28 F. Finocchi and J. Goniakowski, The effects of exchange and correlation on the computed equilibrium shapes of wet MgO crystallites, Surf. Sci., 2007, 601, 4144-4148.

29 G. V. Lewis and C. R. A. Catlow, Potential models for ionic oxides, J. Phys. C Solid State Phys., 1985, 18, 1149-1161.

30 M. Fuchs and M. Scheffler, Ab initio pseudopotentials for electronic structure calculations of poly-atomic systems using density-functional theory, Comput. Phys. Commun., 1999, 119, 67-98.

31 V. Blum, R. Gehrke, F. Hanke, P. Havu, V. Havu, X. Ren, K. Reuter and M. Scheffler, Ab initio molecular simulations with numeric atom-centered orbitals, Comput. Phys. Commun., 2009, 180, 2175-2196.

32 J. D. Gale, GULP: A computer program for the symmetry-adapted simulation of solids, J. Chem. Soc. Faraday Trans., 1997, 93, 629-637.

33 J. D. Gale and A. L. Rohl, The General Utility Lattice Program ( GULP ), Mol. Simul., 2003, 29, 291-341.

34 J. D. Gale, GULP: Capabilities and prospects, Z. Für Krist. - Cryst. Mater., 2005, 220, 552-554.

35 A. A. Sokol, S. T. Bromley, S. A. French, C. R. A. Catlow and P. Sherwood, Hybrid QM/MM embedding approach for the treatment of localized surface states in ionic materials, Int. J. Quantum Chem., 2004, 99, 695-712.

36 J. Kästner, J. M. Carr, T. W. Keal, W. Thiel, A. Wander and P. Sherwood, DL-FIND: An Open-Source Geometry Optimizer for Atomistic Simulations ${ }^{\dagger}$, J. Phys. Chem. A, 2009, 113, 11856-11865.

37 C. Adamo and V. Barone, Toward reliable density functional methods without adjustable parameters: The PBE0 model, J. Chem. Phys., 1999, 110, 6158-6170.

38 A. Logsdail and H. Jenkins, Effect of QM region size and shape in QM/MM calculations for oxide surfaces, Prep.

39 S. J. Blanksby and G. B. Ellison, Bond Dissociation Energies of Organic Molecules, Acc. Chem. Res., 2003, 36, 255-263.

40 R. Włodarczyk, M. Sierka, K. Kwapień, J. Sauer, E. Carrasco, A. Aumer, J. F. Gomes, M. Sterrer and H.-J. Freund, Structures of the Ordered Water Monolayer on $\mathrm{MgO}(001)$, J. Phys. Chem. C, 2011, 115, 6764-6774.

41 S. F. Boys and F. Bernardi, The calculation of small molecular interactions by the differences of separate total energies. Some procedures with reduced errors, Mol. Phys., 1970, 19, 553-566.

42 H. Petitjean, K. Tarasov, F. Delbecq, P. Sautet, J. M. Krafft, P. Bazin, M. C. Paganini, E. Giamello, M. Che, H. Lauron-Pernot and G. Costentin, Quantitative Investigation of 
MgO Brønsted Basicity: DFT, IR, and Calorimetry Study of Methanol Adsorption, J. Phys. Chem. C, 2010, 114, 3008-3016.

43 M. M. Branda, R. M. Ferullo, P. G. Belelli and N. J. Castellani, Methanol adsorption on magnesium oxide surface with defects: a DFT study, Surf. Sci., 2003, 527, 89-99.

44 C. T. Campbell and J. R. V. Sellers, Enthalpies and Entropies of Adsorption on WellDefined Oxide Surfaces: Experimental Measurements, Chem. Rev., 2013, 113, 4106-4135.

45 M. Trabelsi, S. Saidi, C. Chefi, C. Martin, S. Lucas, D. Ferry and J. Suzanne, Thermodynamic and structural study of methanol thin films adsorbed on $\mathrm{MgO}(100)$, Surf. Sci., 2004, 566-568, 789-793.

46 X. D. Peng and M. A. Barteau, Acid-base properties of model magnesium oxide surfaces, Langmuir, 1991, 7, 1426-1431.

47 K. Pathak, K. M. Reddy, N. N. Bakhshi and A. K. Dalai, Catalytic conversion of glycerol to value added liquid products, Appl. Catal. Gen., 2010, 372, 224-238.

48 F. J. Gutiérrez Ortiz, A. Serrera, S. Galera and P. Ollero, Experimental study of the supercritical water reforming of glycerol without the addition of a catalyst, Energy, 2013, 56, 193-206.

49 D. Hernandez, M. Velasquez, P. Ayrault, D. Lopez, J. J. Fernandez, A. Santamaria and C. Batiot-Dupeyrat, Gas phase glycerol conversion over lanthanum based catalysts: $\mathrm{LaNiO}_{3}$ and $\mathrm{La}_{2} \mathrm{O}_{3}$, Appl. Catal. Gen., 2013, 467, 315-324.

50 E. Tsukuda, S. Sato, R. Takahashi and T. Sodesawa, Production of acrolein from glycerol over silica-supported heteropoly acids, Catal. Commun., 2007, 8, 1349-1353. 